\title{
Experimental investigations on the formation of excess air in quasi-saturated porous media
}

\author{
Johannes Holocher,,${ }^{1} *$ Frank Peeters, ${ }^{1}$ Werner Aeschbach-Hertig,,${ }^{1}$ Markus Hofer, ${ }^{1}$ Matthias Brennwald, ${ }^{1}$ \\ WolfGang KinZelbach, ${ }^{2}$ and Rolf KIPFER ${ }^{1,3}$ \\ ${ }^{1}$ Environmental Isotopes Group, Department of Water Resources and Drinking Water, Swiss Federal Institute of Environmental Science and \\ Technology (EAWAG), P.O. Box 611, CH-8600 Dübendorf, Switzerland \\ ${ }^{2}$ Institute of Hydromechanics and Water Resources Management, Swiss Federal Institute of Technology (ETH), ETH Hönggerberg, CH-8093 \\ Zürich, Switzerland \\ ${ }^{3}$ Isotope Geology, Department of Earth Sciences, Swiss Federal Institute of Technology (ETH), NO C61, CH-8092 Zürich, Switzerland
}

\begin{abstract}
The formation of an excess of dissolved gas ("excess air") in quasi-saturated media was studied by analyzing and interpreting dissolved noble gas concentrations in laboratory column experiments. Using quartz sand filled columns of $1 \mathrm{~m}$ length, two different experimental designs were realized. In the first, groundwater recharge was simulated by a unidirectional vertical water flow through the columns. In the second, groundwater level fluctuations in an aquifer zone without active infiltration were reproduced by cyclic water level fluctuations in the columns. The reproducible generation of excess air under these defined, near natural conditions was successful. Partial or complete dissolution of air bubbles entrapped in the quartz sand could be identified as the mechanism responsible for the generation of excess air. Depending on the experimental design, supersaturation of the dissolved atmospheric noble gases ranging between $1.4 \% \Delta \mathrm{Ne}$ and $16.2 \% \Delta \mathrm{Ne}$ was found. The measured noble gas patterns were interpreted using inverse modeling and conceptual gas exchange models and were compared to results of numerical simulations of gas bubble dissolution in water filled soil columns. The gas composition in most of the samples resembles either unfractionated pure atmospheric excess air or is fractionated in accordance with closed-system equilibration between entrapped air and surrounding water. In addition to the amount of entrapped air, the hydrostatic pressure exerted on the entrapped air bubbles is the dominating parameter responsible for the total amount of dissolved air. The composition of the excess air component is controlled by the water flow regime, the bubble size distribution, the initially dissolved gas concentrations and the initially entrapped gas composition.
\end{abstract}

\section{INTRODUCTION}

Supersaturation of atmospheric gases in groundwater is ubiquitous and manifest in the concentrations of the inert atmospheric noble gases. Since the composition of the dissolved gas excess is often similar to that of atmospheric air, Heaton and Vogel (1981) introduced the term "excess air" for this phenomenon. Excess air was first described by Mazor (1972) for thermal waters of the Jordan Rift Valley, and by Oana (1957), Andrews and Lee (1979) and Heaton and Vogel (1979) in sedimentary aquifers. Whenever trace gases with a low solubility in groundwater are considered, excess air plays an important role. In these cases, usually the equilibrium concentration of the considered gas has to be determined, which implies that the excess air component has to be separated from the total measured dissolved gas concentration. Examples of trace gas methods in groundwater which are sensitive to excess air are the dating of groundwater with ${ }^{3} \mathrm{H}-{ }^{3} \mathrm{He}$ (Schlosser et al., 1988; Stute et al., 1997; Aeschbach-Hertig et al., 1998) and $\mathrm{SF}_{6}$ (Busenberg and Plummer, 2000), and the determination of paleorecharge conditions, especially the infiltration temperature (Mazor, 1972; Andrews and Lee, 1979; Stute and Schlosser, 1993; Stute et al., 1995). Besides the relevance of excess air for trace gas methods in groundwater, the excess air component itself most probably conveys information about past climatic

* Author to whom correspondence should be addressed (johannes.holocher@eawag.ch). and recharge conditions as well as aquifer characteristics (Heaton et al., 1986; Wilson and McNeill, 1997; Stute and Talma, 1998; Aeschbach-Hertig et al., 2001). Finally, excess air in groundwater is also important for the biogeochemistry of the transition zone between groundwater and unsaturated zone. As excess air comprises all air components, i.e., also the main air constituents oxygen and nitrogen, a dissolved oxygen source in the uppermost aquifer zone exists which is usually not considered, although it may significantly contribute to the oxygen availability in a groundwater body. Note that the biogeochemical reactivity of oxygen in most cases prevents the direct detection of the excess air component in the dissolved oxygen concentrations in aquifer systems.

Since its first recognition in porous aquifers, the formation of excess air has usually been explained by the complete dissolution of entrapped air bubbles under the influence of the hydrostatic pressure (Heaton and Vogel, 1981). The air entrapment in porous media during water saturation is a well-known effect (e.g., Christiansen, 1944; Faybishenko, 1995). As air entrapment occurs regularly in groundwater systems due to cyclic or periodic water level fluctuations, the dissolution of parts of this additional reservoir of atmospheric gases is most likely and as a result may lead to the excess air component in groundwater.

This concept of linking the dissolution of entrapped air to the formation of excess air has never been directly proven. A detailed knowledge of the processes involved in excess air generation and the identification of the relevant parameters controlling these processes is still lacking. Apart from some 
Table 1. Molecular diffusivities and dimensionless Henry coefficients.

\begin{tabular}{llllccc}
\hline & $5{ }^{\circ} \mathrm{C}$ & $15{ }^{\circ} \mathrm{C}$ & $25{ }^{\circ} \mathrm{C}$ & $5{ }^{\circ} \mathrm{C}$ & $15{ }^{\circ} \mathrm{C}$ & $25{ }^{\circ} \mathrm{C}$ \\
\hline \multicolumn{5}{c}{$\mathrm{D}\left[10^{-5} \mathrm{~cm}^{2} / \mathrm{s}\right]$} & \multicolumn{2}{c}{$\mathrm{K}_{\mathrm{H}}[(\mathrm{mol} / 1 \mathrm{lgas}) /(\mathrm{mol} / 1$ water $)]$} \\
\hline $\mathrm{He}$ & 5.10 & 6.30 & 7.22 & 107 & 107 & 105 \\
$\mathrm{Ne}$ & 2.61 & 3.28 & 4.16 & 83.4 & 88.0 & 90.7 \\
$\mathrm{Ar}$ & 1.63 & 2.13 & 2.69 & 20.9 & 25.2 & 29.3 \\
$\mathrm{Kr}$ & 1.02 & 1.41 & 1.84 & 10.5 & 13.4 & 16.4 \\
$\mathrm{Xe}$ & 0.774 & 1.12 & 1.47 & 5.36 & 7.29 & 9.41 \\
${ }^{3} \mathrm{He}$ & 5.89 & 6.33 & 7.25 & 109 & 109 & 107 \\
${ }^{4} \mathrm{He}$ & 5.10 & 6.30 & 7.22 & 107 & 107 & 105 \\
${ }^{20} \mathrm{Ne}$ & 2.62 & 3.29 & 4.18 & 83.4 & 88.0 & 90.7 \\
${ }^{22} \mathrm{Ne}$ & 2.50 & 3.14 & 3.98 & 83.2 & 88.0 & 90.5 \\
$\mathrm{~N}_{2}$ & 1.11 & 1.49 & 1.96 & 46.8 & 55.6 & 63.5 \\
$\mathrm{O}_{2}$ & 1.36 & 1.80 & 2.35 & 22.9 & 27.7 & 32.2 \\
\hline
\end{tabular}

D: Molecular diffusivites in water. Measured values for $\mathrm{He}, \mathrm{Ne}, \mathrm{Kr}$ and Xe were taken from Jähne et al. (1987). The diffusivity of Ar was approximated by the relationship $\mathrm{D}_{\mathrm{i}} \sim 1 /\left(\text { mass }_{\mathrm{i}}\right)^{0.5}$ using the measured values of $\mathrm{He}, \mathrm{Ne}, \mathrm{Kr}$ and $\mathrm{Xe}$. Diffusivities of oxygen and nitrogen were taken from Broecker and Peng (1974).

$\mathrm{K}_{\mathrm{H}}$ : Dimensionless Henry coefficients. They are calculated using the equilibrium concentrations assuming $\mathrm{P}=1 \mathrm{~atm}$ and $\mathrm{S}=0$ from Weiss (1970), Weiss (1971), Weiss and Kyser (1978) and Benson and Krause (1980) for ${ }^{3} \mathrm{He},{ }^{4} \mathrm{He}, \mathrm{Ne}, \mathrm{Ar}$ and $\mathrm{Kr}$, and from Clever (1979) for Xe. For ${ }^{3} \mathrm{He}$ and ${ }^{22} \mathrm{Ne}$, the fractionation factors given by Beyerle et al (2000) were used. The values for ${ }^{4} \mathrm{He}$ and ${ }^{20} \mathrm{Ne}$ were assumed to correspond to those of $\mathrm{He}$ and $\mathrm{Ne}$, respectively.

work in the 1980s (Tegen, 1988; Gröning, 1989; Osenbrück, 1991), conclusive investigations on the generation of excess air under defined laboratory conditions have never been conducted. In this study we therefore performed laboratory column experiments to (1) reproducibly generate excess air; (2) identify the relevant mechanism that leads to excess air; and (3) identify the underlying physical parameters controlling the excess air formation.

\section{THEORY}

Noble gas concentrations in natural waters are basically the result of the dissolution of atmospheric gases according to Henry's law:

$$
C_{i}^{*}=\frac{C_{i}^{\text {gas }}}{K_{H, i}(T, S)}=\frac{p_{i}}{R \cdot T \cdot K_{H, i}(T, S)}
$$

The equilibrium concentration $C_{i}^{*}$ of the dissolved gas $i$ in solution is directly proportional to its atmospheric concentration $C_{i}^{\text {gas }}$. The molar atmospheric concentration is related to the partial pressure $p_{i}$ in the gas phase according to Dalton's Law in which $R$ is the universal gas constant. The concentration proportionality is given by the dimensionless Henry coefficient $K_{H, i}$ which depends on temperature $T$ and salinity $S$. For the chemically inert noble gases, hence the equilibrium gas concentrations convey information about the water temperature at the time of infiltration (e.g., Stute and Schlosser, 1993).

The atomic mass of the noble gases influences their behavior in air-water partitioning (Table 1). On the one hand, the solubility of the noble gases increases with increasing atomic mass. As a result, in solubility equilibrium with the atmosphere the dissolved gas composition is enriched in the heavy gases relative to atmospheric air. On the other hand, the molecular diffusivity of the noble gases in water decreases with increasing atomic mass. This implies that any diffusive alterations of dissolved noble gas concentrations have the strongest effect on the light noble gases.

The addition of atmospheric air to solubility equilibrium concentrations yields a characteristic supersaturation pattern in which the least soluble light noble gases show the largest excess (Table 2). The dissolved concentration of gas $i$ in case of an excess of unfractionated atmospheric air can be described as follows (e.g., Heaton and Vogel, 1981):

$$
C_{i}\left(T, S, P, A_{U A}\right)=C_{i}^{*}(T, S, P)+A_{U A} \cdot z_{i}
$$

In this unfractionated excess air (UA) model $A_{U A}$ is the concentration of dissolved dry air in water, $z_{i}$ is the volume fraction of the considered gas in dry air, and $C_{i}^{*}$ is the moist air solubility equilibrium concentration at the given temperature $T$, atmospheric pressure $P$ and salinity $S$. For more information about the calculation of $C_{i}^{*}$ refer to Aeschbach-Hertig et al. (1999).

Assuming that water entering the groundwater is in equilibrium with the (soil-) atmosphere, a dissolved gas excess of purely atmospheric composition can only be realized by the complete dissolution of an additional air volume. Since the solubilities as well as the temperature dependency of the Henry coefficient $K_{H, i}$ of the noble gases increase with increasing molecular weight, other possible mechanisms leading to supersaturation of dissolved gas in groundwater (mixing of water components that equilibrated at different temperatures, changes in the parameters $T, S$ and $P$ that define the solubility equilibrium concentration, in-situ gas production and changes in the individual partial pressures) result in dissolved elemental noble gas patterns that differ from the pure excess air signature corresponding to air injection (Table 2).

In contrast to the simple concept of complete air bubble dissolution, groundwaters sometimes show a different type of excess air composition. In this case, the gas excess exhibits a systematic, mass-dependent fractionation relative to atmospheric air which can be characterized as an increasing enrichment or decreasing depletion with increasing atomic mass. Possible mechanisms leading to such type of "fractionated excess air" are the partial diffusive degassing of an initial excess with atmospheric composition across the groundwater table (Partial re-equilibration, Stute et al., 1995), or the equilibration of a finite water volume with a finite air volume under increased pressure (Closed-system equilibration, AeschbachHertig et al., 2000).

In the first case, an initially dissolved gas excess is partially lost, either to the gas phase of the soil air across the groundwater table or during the flow process within the aquifer. As the diffusivities in water are the greater the lighter the gas is, this diffusive re-equilibration affects the light noble gases most. The partial re-equilibration model that describes the effect of a diffusively controlled gas loss considers as model parameters the amount of initially dissolved excess air $A_{P R}$ and the degree of elemental fractionation $F_{P R}$ (Stute et al., 1995; AeschbachHertig et al., 1999):

$$
C_{i}\left(T, S, P, A_{P R}, F_{P R}\right)=C_{i}^{*}(T, S, P)+A_{P R} \cdot z_{i} \cdot e^{\left(-F_{P R} \frac{D_{i}}{D_{N e}}\right)}
$$


Table 2. Noble gas composition of air and air-saturated water.

\begin{tabular}{|c|c|c|c|c|c|}
\hline & $\mathrm{He}$ & $\mathrm{Ne}$ & $\mathrm{Ar}$ & $\mathrm{Kr}$ & $\mathrm{Xe}$ \\
\hline Vol. fract. $z_{i}$ in dry air $[-]$ & $5.24 \cdot 10^{-6}$ & $1.818 \cdot 10^{-5}$ & $9.34 \cdot 10^{-3}$ & $1.14 \cdot 10^{-6}$ & $8.7 \cdot 10^{-8}$ \\
\hline $\mathrm{Z}_{\mathrm{i}} / \mathrm{z}_{\mathrm{He}}$ & 1 & 3.47 & 1782 & 0.22 & 0.017 \\
\hline $\mathrm{C}^{*}\left[\mathrm{~cm}^{3} \mathrm{STP} / \mathrm{g}\right]$ & $4.243 \cdot 10^{-8}$ & $1.754 \cdot 10^{-7}$ & $2.956 \cdot 10^{-4}$ & $6.603 \cdot 10^{-8}$ & $9.019 \cdot 10^{-9}$ \\
\hline $\mathrm{C}_{\mathrm{i}}^{*} / \mathrm{C}_{\mathrm{He}}^{*}$ & 1 & 4.13 & 6968 & 1.56 & 0.21 \\
\hline Parameter changes relative to $\mathrm{C}^{*}$ & $\Delta \mathrm{He}[\%]$ & $\Delta \mathrm{Ne}[\%]$ & $\Delta \operatorname{Ar}[\%]$ & $\Delta \mathrm{Kr}[\%]$ & $\Delta \mathrm{Xe}[\%]$ \\
\hline$\Delta \mathrm{T}=1.0^{\circ} \mathrm{C}$ & -0.33 & -0.77 & -1.94 & -2.45 & -2.96 \\
\hline$\Delta \mathrm{S}=1 \%$ & -0.52 & -0.56 & -0.67 & -0.70 & -0.72 \\
\hline$\Delta \mathrm{P}=0.01 \mathrm{~atm}$ & 1.08 & 1.08 & 1.08 & 1.08 & 1.08 \\
\hline$\Delta \mathrm{A}=10^{-4} \mathrm{~cm}^{3} \mathrm{STP} / \mathrm{g}$ & 1.24 & 1.04 & 0.32 & 0.17 & 0.10 \\
\hline
\end{tabular}

$\mathrm{Z}_{\mathrm{i}}$ : Volume fraction of gas $\mathrm{i}$ in the atmosphere $[-]$.

$\mathrm{C}_{\mathrm{i}}^{*}$ : Concentration of gas $\mathrm{i}$ in air-saturated water at solubility equilibrium at $20{ }^{\circ} \mathrm{C}, 435 \mathrm{~m} \mathrm{a}$. $\mathrm{s}$. 1 . and zero salinity [cm ${ }^{3} \mathrm{STP} / \mathrm{g}$ water].

$\mathrm{T}$ : Water temperature $\left[{ }^{\circ} \mathrm{C}\right]$.

S: Salinity $[\% o]$.

P: Pressure [atm].

A: Dissolved air $\left[\mathrm{cm}^{3} \mathrm{STP} / \mathrm{g}\right.$ water].

$\Delta$ Noblegas: Changes in the noble gas pattern induced by specified changes in the parameters $T, S, P$ and $A$, relative to the given solubility equilibrium concentration $C^{*}$.

$F_{P R}$ can be interpreted as being proportional to the time during which the initial supersaturation is lost to the soil air. Fractionation of the gas excess in the PR-model is solely due to differences in molecular diffusivities between the gases.

The CE concept assumes a closed system in which a finite water volume equilibrates with a finite entrapped air volume under increased pressure. If the air volume is completely dissolved, the result is pure, unfractionated excess air. If not, the elemental compositions of both the dissolved gas and the remaining gas volume are fractionated depending on the initial air-water volume ratio and the pressure on the system. As a result, the heavy noble gases $\mathrm{Ar}, \mathrm{Kr}$ and $\mathrm{Xe}$ are enriched in the water phase relative to the light noble gases $\mathrm{He}$ and $\mathrm{Ne}$. The CE- model also uses two parameters to describe the fractionation process: $A_{C E}$ gives the initial amount of entrapped air, $F_{C E}$ the reduction of volume of entrapped air due to dissolution (Aeschbach-Hertig et al., 2000):

$$
\begin{aligned}
& C_{i}\left(T, S, P, A_{C E}, F_{C E}\right)=C_{i}^{*}(T, S, P) \\
&+\frac{\left(1-F_{C E}\right) \cdot A_{C E} \cdot z_{i}}{1+F_{C E} A_{C E} z_{i} / C_{i}^{*}(T, S, P)}
\end{aligned}
$$

The parameter $F_{C E}$ can be decomposed into the parameters $v$ describing the reduction of the entrapped air volume due to partial dissolution, and $1 / q$ describing the effect of compression on the discrete gas phase. Fractionation according to the CEmodel does not depend on the molecular diffusivities but on the differences between the Henry coefficients of different gases and on the variations in the ratio of water volume to volume of entrapped air.

These conceptual approaches which reasonably reproduce the atmospheric noble gas abundance in natural waters (Aeschbach-Hertig et al., 1999) focus on the final state of gas exchange between entrapped air, soil air and groundwater without an explicit consideration of the processes that lead to this state. Because the models do not include microscopic kinetics and details such as the spatial and size distribution of the bubbles, they may be seen as simplified "lumped-parameter" models. Alternatively, the gas exchange and the partitioning between entrapped air bubbles and groundwater can be described in kinetic terms. Therein, the mass exchange of the five noble gases as well as of the main air constituents oxygen and nitrogen are simulated numerically for spherical air bubbles entrapped in an aquifer column. The air-water mass transfer is modeled assuming a rapid equilibration between the two phases according to Henry's law and a water-side boundary layer gas exchange concept (Schwarzenbach et al., 1993). For one initial bubble size, the temporal change in dissolved concentration of gas $i$ is given by:

$$
\begin{aligned}
\frac{d C_{i}}{d t}= & \frac{A_{\text {int }}}{\frac{V_{\text {tot }} \cdot \theta}{\left(1+r_{\text {air-water }}\right)}} \frac{D_{i}}{\delta_{\text {eff }}}\left(C_{i}-C_{i}^{*}\right)=\frac{A_{\text {int }}}{\frac{V_{\text {tot }} \cdot \theta}{\left(1+r_{\text {air-water }}\right)}} \frac{D_{i}}{\delta_{\text {eff }}} \\
& \left(C_{i}-\frac{x_{i}\left(P-p_{w}+\rho g h+2 \sigma / r\right)}{R T K_{H, i}}\right)
\end{aligned}
$$

where $A_{\text {int }}$ is the total interface area between water and entrapped air bubbles $\left[\mathrm{m}^{2}\right], V_{\text {tot }}$ the total volume of the considered aquifer column $\left[\mathrm{m}^{3}\right], \theta$ is the porosity $[-], r_{\text {air-water }}$ is the ratio of the entrapped air volume and water volume $[-], D_{i}$ is the diffusivity of the gas in water $\left[\mathrm{m}^{2} \cdot \mathrm{s}^{-1}\right], \delta_{\text {eff }}$ is the effective boundary layer thickness around the air bubbles $[\mathrm{m}], C_{i}$ is the actual dissolved concentration and $C_{i}^{*}$ the moist air solubility equilibrium concentration of gas $i\left[\mathrm{~mol} \cdot \mathrm{m}^{-3}\right], x_{i}$ is the actual mole fraction of the gas in the bubble. $P$ is the atmospheric pressure $[\mathrm{Pa}], p_{w}$ is the partial pressure of water vapor in the bubble $[\mathrm{Pa}], \rho g h$ is the hydrostatic pressure in the water at depth $h[\mathrm{~Pa}], 2 \sigma / r$ is the capillary pressure resulting from the curvature of the bubble surface [Pa], $\sigma$ is the surface tension $[\mathrm{Pa} \cdot \mathrm{m}], R$ is the universal gas constant $\left[\mathrm{Pa} \cdot \mathrm{m}^{3} \cdot \mathrm{K}^{-1} \cdot \mathrm{mol}^{-1}\right], T$ is the water temperature [K] and $K_{H, i}$ is the dimensionless Henry coefficient of gas $i$.

Initially, the water is assumed to be in solubility equilibrium with the atmosphere at given $T, P$ and $S$. The hydrostatic pressure at depth $h$ and the capillary pressure $2 \sigma / r$ combine to an excess pressure that is exerted on a considered entrapped air bubble in the water column. Thus the bubble will dissolve until-in accordance with the actual pressure-a new equilibrium between the gas phase in the bubble and the dissolved 
Table 3. Quartz sand properties.

\begin{tabular}{lccc}
\hline \multicolumn{1}{c}{ Quartz sand } & Fine & Medium & Coarse \\
\hline Particle diameter & $0.1-0.3 \mathrm{~mm}$ & $0.315-0.63 \mathrm{~mm}$ & $1.0-1.7 \mathrm{~mm}$ \\
Porosity & 0.42 & 0.40 & 0.38 \\
$\mathrm{~V}_{\text {Entrapped }} / \mathrm{V}_{\text {Pore }}$ & 0.08 & 0.09 & 0.01 \\
$\mathrm{~V}_{\text {Immobile }} / \mathrm{V}_{\text {Pore }}$ & 0.76 & 0.26 & 0.22 \\
\hline
\end{tabular}

$\mathrm{V}_{\text {Entrapped }}$ : Gravimetrically determined initially entrapped air volume.

$\mathrm{V}_{\text {Pore }}$ : Total pore volume of a given sample volume determined gravimetrically using a quartz sand density of $2.65 \mathrm{~g} / \mathrm{cm}^{3}$.

$\mathrm{V}_{\text {Immobile }}$ : Gravimetrically determined immobile water volume after water drainage.

components in the surrounding water is reached. The dissolved gas composition of this new equilibrium state is determined by the initial conditions and the solubilities of the gases. The molecular diffusivities affect the gas composition only during the transition between initial and final state. Because this transition time is rather short, the noble gas concentrations observed in groundwater samples usually reflect the composition in the final equilibrated state.

The air bubble-water mass transfer is coupled with a onedimensional advective-diffusive transport model allowing variable and adequate discretization in space and time. As a result, the interaction of entrapped air bubbles with flowing or stagnant water can be simulated kinetically providing insights into the temporal development of the air bubble sizes and the gas composition in both the entrapped air bubbles and in the dissolved gas phase. A more detailed description of the kinetic air bubble dissolution (KBD)-model will soon be given elsewhere.

\section{EXPERIMENTAL}

Laboratory experiments studying the formation of excess air were performed using packed sand columns. The acrylic glass columns had a length of $1 \mathrm{~m}$ and an inner diameter of $5.2 \mathrm{~cm}$ with two sampling ports at the bottom and in the middle, i.e., at $50 \mathrm{~cm}$ height. They were filled with clean, well-sorted quartz sand up to $80 \mathrm{~cm}$ above the column bottom. Quartz sand with particle sizes ranging from $0.315 \mathrm{~mm}$ to $0.63 \mathrm{~mm}$ was employed. Additionally, a coarser (particle sizes between $1.0 \mathrm{~mm}$ and $1.7 \mathrm{~mm}$ ) and a finer quartz sand (particle sizes between 0.1 $\mathrm{mm}$ and $0.3 \mathrm{~mm}$ ) were used. The total porosity, the entrapped air volume after water saturation and the immobile water volume after drainage were determined gravimetrically (Table 3). For the intermediate sized quartz sand, the pore size spectrum after water saturation was measured with a low-field NMR instrument (Chen and Kinzelbach, 2002). The spectrum shows a unimodal skew pore diameter distribution between $50 \mu \mathrm{m}$ and $800 \mu \mathrm{m}$ with a weighted average diameter of $300 \mu \mathrm{m}$.

Two different experimental series were performed (Fig. 1). In the first, the columns were water saturated from bottom to top. After this first imbibition, a constant vertical water flow with different flow velocities in the various experiments was established. The water level in the columns was kept constant at $80 \mathrm{~cm}$ above the column bottom. Water samples were taken from the bottom sampling port at different time intervals.

The second series of experiments consisted of cyclic water level fluctuations in the columns. Each sand column was initially filled with equilibrated water to the top of the sand-filled column section. After a stagnation phase, the water was drained out of the column into a closed water vessel down to a minimal water level a few centimeters above the column bottom. In the next step, the water from the vessel was used to refill the sand column. Several experiments with various numbers of water saturation and drainage steps were performed. Samples were taken from both the bottom and the middle sampling port. The amount of water in the system during the water level fluctuations was constant. The water level changes were achieved by adjusting the height of the water vessel (Fig. 1).

In all experiments de-ionized water being initially in solubility equilibrium with the atmosphere was used. The equilibrium was attained by slow stirring of water in an open reservoir

\section{Through Flow}

\section{Water Level Fluctuations}

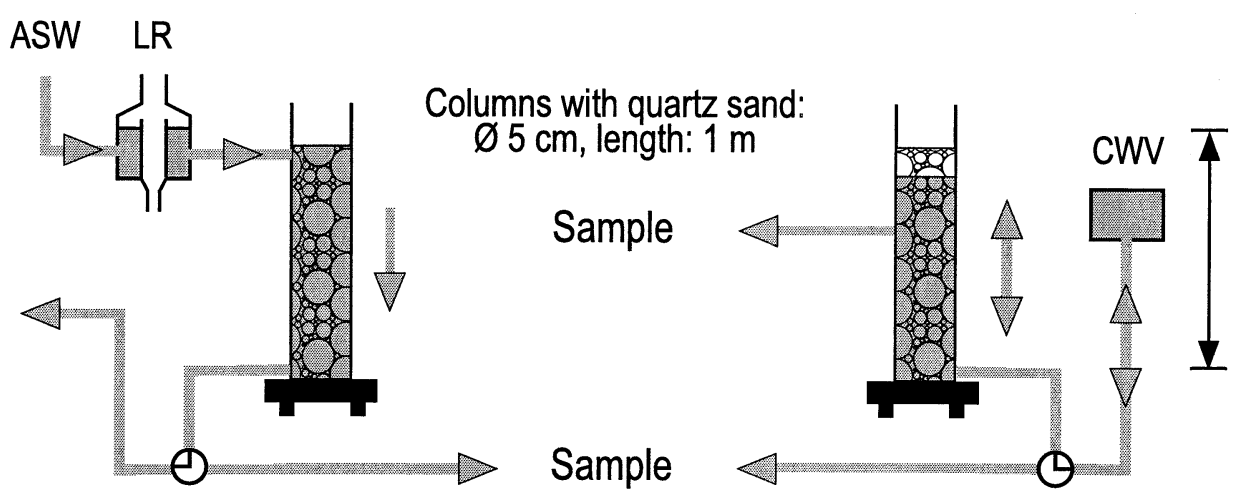

Fig. 1. Experimental setup: Two different series of column experiments were performed: (1) Throughflow experiments where air-saturated water (ASW) flows through the quartz sand filled column. The water level is kept constant using a leveling reservoir LR. (2) In the water level fluctuation experiments the column was periodically water saturated and drained, thereby the total water volume in the column (closed water vessel CWV + column) is kept constant. 
Table 4. Noble gas concentrations of the water throughflow experiments.

\begin{tabular}{|c|c|c|c|c|c|c|c|c|c|c|c|c|}
\hline Sample & ST & $\mathrm{FV}$ & $\begin{array}{c}\mathrm{He} \\
{\left[10^{-8}\right]}\end{array}$ & $\begin{array}{c}\mathrm{Ne} \\
{\left[10^{-7}\right]}\end{array}$ & $\underset{\left[10^{-4}\right]}{\mathrm{Ar}}$ & $\underset{\left[10^{-8}\right]}{\mathrm{Kr}}$ & $\begin{array}{c}\mathrm{Xe} \\
{\left[10^{-9}\right]}\end{array}$ & ${ }^{4} \mathrm{He} /{ }^{20} \mathrm{Ne}$ & ${ }^{22} \mathrm{Ne} /{ }^{20} \mathrm{Ne}$ & $\begin{array}{c}\text { Excess air } \\
\text { model }\end{array}$ & $\begin{array}{c}\mathrm{T} \\
\text { predicted }\end{array}$ & $\Delta \mathrm{Ne}$ \\
\hline & $\mathrm{h}$ & $\mathrm{cm} / \mathrm{h}$ & \multicolumn{5}{|c|}{$\mathrm{cm}^{3} \mathrm{STP} / \mathrm{g} \mathrm{H}_{2} \mathrm{O}$} & {$[-]$} & {$[-]$} & & ${ }^{\circ} \mathrm{C}$ & $\%$ \\
\hline TM1 & 3 & 110 & 4.65 & 1.90 & 3.11 & 6.81 & 9.30 & 0.2709 & 0.1023 & $\mathrm{UA}(\mathrm{T}, \mathrm{A})$ & $19.5 \pm 0.2$ & 6.2 \\
\hline TM2 & 4 & 20 & 4.82 & 1.98 & 3.15 & 6.87 & 9.02 & 0.2692 & 0.1019 & $\mathrm{CE}(\mathrm{A}, \mathrm{F})$ & 20 & 13.6 \\
\hline TM3 & 4 & 40 & 4.82 & 1.98 & 3.16 & - & 9.15 & 0.2697 & 0.1023 & $\mathrm{UA}(\mathrm{A})$ & 20 & 11.1 \\
\hline TM4 & 4 & 80 & 4.67 & 1.91 & 3.08 & 6.68 & 8.94 & 0.2702 & 0.1022 & $\mathrm{UA}(\mathrm{T}, \mathrm{A})$ & $19.8 \pm 0.1$ & 7.2 \\
\hline TM5 & 7 & 20 & 4.61 & 1.90 & 3.16 & 6.96 & 9.47 & 0.2689 & 0.1022 & $\mathrm{CE}(\mathrm{A}, \mathrm{F})$ & 20 & 6.6 \\
\hline TM6 & 8 & 20 & 4.69 & 1.97 & 3.12 & 6.83 & 9.18 & 0.2632 & 0.1017 & $\mathrm{CE}(\mathrm{T}, \mathrm{A}, \mathrm{F})$ & $20.6 \pm 1.1$ & 11.2 \\
\hline TM7-I & 8 & 10 & 4.63 & 1.92 & 3.24 & 7.07 & 9.31 & 0.2660 & 0.1023 & $\mathrm{CE}(\mathrm{T}, \mathrm{A}, \mathrm{F})$ & $19.0 \pm 1.1$ & 7.3 \\
\hline TM7-II & 16 & 10 & 4.67 & 1.94 & 3.19 & 6.96 & 9.36 & 0.2660 & 0.1024 & $\mathrm{CE}(\mathrm{T}, \mathrm{A}, \mathrm{F})$ & $19.5 \pm 1.0$ & 8.6 \\
\hline TM7-III & 24 & 10 & 4.82 & 1.98 & 3.15 & 6.83 & 9.07 & 0.2690 & 0.1023 & $\mathrm{CE}(\mathrm{T}, \mathrm{A}, \mathrm{F})$ & $21.0 \pm 0.9$ & 12.3 \\
\hline TM8-I & 3 & 30 & 4.73 & 1.94 & 3.12 & 6.82 & 9.18 & 0.2700 & 0.1023 & $\mathrm{CE}(\mathrm{T}, \mathrm{A}, \mathrm{F})$ & $20.7 \pm 0.9$ & 9.5 \\
\hline TM8-II & 6 & 30 & 4.81 & 1.96 & 3.11 & 6.74 & 9.10 & 0.2707 & 0.10210 & $\mathrm{CE}(\mathrm{T}, \mathrm{A}, \mathrm{F})$ & $20.9 \pm 0.8$ & 11.1 \\
\hline TM9-III & 24 & 30 & 4.89 & 2.01 & 3.12 & 6.83 & 9.15 & 0.2691 & 0.1023 & $\mathrm{UA}(\mathrm{T}, \mathrm{A})$ & $19.8 \pm 0.2$ & 12.7 \\
\hline TM9-I & 2 & 50 & 4.85 & 1.98 & 3.17 & 6.97 & 9.28 & 0.2713 & 0.1023 & $\mathrm{CE}(\mathrm{T}, \mathrm{A}, \mathrm{F})$ & $21.5 \pm 1.0$ & 13.2 \\
\hline TM9-II & 7 & 50 & 4.93 & 1.99 & 3.15 & 6.74 & 9.10 & 0.2739 & 0.1023 & $\mathrm{UA}(\mathrm{T}, \mathrm{A}, \mathrm{F})$ & $19.8 \pm 0.3$ & 11.6 \\
\hline TF10-I & 4 & 10 & 4.86 & 1.98 & 3.20 & 6.81 & 9.28 & 0.2712 & 0.1023 & $\mathrm{CE}(\mathrm{A}, \mathrm{F})$ & 20 & 13.4 \\
\hline TF10-II & 8 & 10 & 4.78 & 1.99 & 3.15 & 6.81 & - & 0.2659 & 0.1019 & $\mathrm{CE}(\mathrm{A}, \mathrm{F})$ & 20 & 11.7 \\
\hline TF10-III & 24 & 10 & 4.96 & 2.06 & 3.15 & 6.82 & 9.33 & 0.2660 & 0.1021 & $\mathrm{CE}(\mathrm{A}, \mathrm{F})$ & 20 & 15.8 \\
\hline TF10-IV & 32 & 10 & 4.99 & 2.05 & 3.14 & 6.89 & 9.32 & 0.2685 & 0.1023 & $\mathrm{UA}(\mathrm{T}, \mathrm{A})$ & $19.6 \pm 0.4$ & 15.0 \\
\hline TC11-I & 8 & 10 & 4.92 & 2.03 & 3.20 & 7.00 & 9.52 & 0.2676 & 0.1020 & $\mathrm{CE}(\mathrm{T}, \mathrm{A}, \mathrm{F})$ & $19.6 \pm 0.8$ & 13.9 \\
\hline TC11-II & 24 & 10 & 4.90 & 2.03 & 3.14 & 6.83 & 9.31 & 0.2662 & 0.1023 & $\mathrm{CE}(\mathrm{A}, \mathrm{F})$ & 20 & 14.4 \\
\hline Equi & - & - & 4.29 & 1.76 & 2.97 & 6.67 & 9.06 & 0.2679 & 0.1023 & $\mathrm{~T}$ & $20.4 \pm 0.1$ & - \\
\hline
\end{tabular}

Sample: T: Throughflow experiment. M: Medium-sized quartz sand (diameter 0.315-0.63 mm). C: Coarse quartz sand (diameter 1.0-1.7 mm). F: Fine quartz sand (diameter 0.1-0.3 mm). Equi: Average concentration of the equilibrated water used in the experiments.

ST: Sampling time after experiment start.

FV: Flow velocity.

Excess Air Model: UA: Unfractionated excess air model. CE: Closed system equilibration model (Aeschbach-Hertig et al., 2000).

$\mathrm{T}$ predicted: Noble gas temperature as predicted by the different excess air models. If $\mathrm{T}$ is not included in the optimization procedure, it is set to $20{ }^{\circ} \mathrm{C}$.

$\Delta \mathrm{Ne}$ : Ne supersaturation with regard to the determined noble gas temperature.

Analytical precision: $\mathrm{He}: 0.4 \%$; $\mathrm{Ne}, \mathrm{Ar}: 1 \%$; $\mathrm{Kr}, \mathrm{Xe}: 1.5 \%$.

$(25 \mathrm{~L})$ for two weeks and was regularly controlled by analyses of the dissolved noble gases. In addition, noble gas concentrations in the laboratory air were measured to verify that the noble gas abundance corresponded to atmospheric composition. Biologic activity in the columns was avoided by adding 4 $\mathrm{mg} / \mathrm{L} \mathrm{CuSO}_{4}$ to the equilibrated water. The air temperature $\left(20^{\circ} \mathrm{C} \pm 0.5^{\circ} \mathrm{C}\right)$ as well as the relative humidity $(90 \%)$ was kept constant in all experiments. The atmospheric pressure in the laboratory is given by its elevation of $435 \mathrm{~m}$ above sea level.

For noble gas analysis, $45 \mathrm{~mL}$ of water were sealed-off in copper tubes under careful prevention of air contamination and degassing (Beyerle et al., 2000). The samples were analyzed for dissolved $\mathrm{He}, \mathrm{Ne}, \mathrm{Ar}, \mathrm{Kr}, \mathrm{Xe}$ and the isotope ratios ${ }^{3} \mathrm{He} /{ }^{4} \mathrm{He}$, ${ }^{20} \mathrm{Ne} /{ }^{22} \mathrm{Ne}$ and ${ }^{36} \mathrm{Ar} /{ }^{40} \mathrm{Ar}$ (Beyerle et al., 2000). The interpretation of the measured noble gas concentrations in terms of the physical conditions prevailing air-water partitioning was based on the least-square optimization procedure of Aeschbach-Hertig et al. (1999). This procedure simultaneously estimates the equilibration temperature, the dissolved concentration and the possible fractionation of excess in a sample by inverse fitting. During all experiments caution was taken to prevent access of non-atmospheric He. As the analyzed $\mathrm{He}$ is only of atmospheric origin, it can be included in the comprehensive interpretation of the dissolved noble gases with regard to excess air formation. In contrast, in virtually all studies of natural groundwaters, the interpretation of He concentrations in terms of recharge conditions is prevented by the presence of non-atmospheric $\mathrm{He}$ sources, such as radiogenic ${ }^{4} \mathrm{He}$ from $\alpha$-decays in the U- and Th-series in the rock matrix.

\section{RESULTS}

The noble gas concentrations of the column experiments are summarized in Table 4 and Table 5. All concentrations are enriched relative to air-saturated water at $20^{\circ} \mathrm{C}$. The amount of supersaturation ranges from $1.4 \%$ to $16.2 \% \Delta \mathrm{Ne}$ which corresponds in case of unfractionated excess air to $1.4 \cdot 10^{-4}$ to $16.2 \cdot 10^{-4} \mathrm{~cm}^{3} \mathrm{STP} / \mathrm{g}$ dissolved excess air. To interpret the measured concentrations in terms of the physical conditions that control the soil air-water gas exchange, the least-square optimization routine NOBLE was used considering $\mathrm{He}, \mathrm{Ne}, \mathrm{Ar}$, $\mathrm{Kr}, \mathrm{Xe}$ and the isotope ratios ${ }^{20} \mathrm{Ne} /{ }^{22} \mathrm{Ne}$ and ${ }^{36} \mathrm{Ar} /{ }^{40} \mathrm{Ar}$. A detailed description of NOBLE will soon be given in this journal. The noble gas temperature was usually treated as unknown model parameter in addition to the parameters A and $\mathrm{F}$ describing the excess air. However, if for a sample no statistically acceptable fit could be achieved, the temperature was set to $20^{\circ} \mathrm{C}$ in accordance with the constant air temperature of $20^{\circ} \mathrm{C} \pm 0.5^{\circ} \mathrm{C}$ in the laboratory, resulting in a stronger constraint on the remaining two unknown parameters.

Samples of the stirred water reservoir over the study period confirm that this water is in atmospheric solubility equilibrium. The average air-saturated concentrations of the equilibrated 
Table 5. Noble gas concentrations of the water level fluctuation experiments.

\begin{tabular}{|c|c|c|c|c|c|c|c|c|c|c|c|c|}
\hline Sample & ST & $\begin{array}{l}\text { Sampling } \\
\text { history }\end{array}$ & $\begin{array}{c}\mathrm{He} \\
{\left[10^{-8}\right]}\end{array}$ & $\begin{array}{c}\mathrm{Ne} \\
{\left[10^{-7}\right]}\end{array}$ & $\underset{\left[10^{-4}\right]}{\mathrm{Ar}}$ & $\begin{array}{c}\mathrm{Kr} \\
{\left[10^{-8}\right]}\end{array}$ & $\begin{array}{c}\mathrm{Xe} \\
{\left[10^{-9}\right]}\end{array}$ & ${ }^{4} \mathrm{He} /{ }^{20} \mathrm{Ne}$ & ${ }^{22} \mathrm{Ne} /{ }^{20} \mathrm{Ne}$ & $\begin{array}{c}\text { Excess air } \\
\text { model }\end{array}$ & $\begin{array}{c}\mathrm{T} \\
\text { predicted }\end{array}$ & $\Delta \mathrm{Ne}$ \\
\hline & $\mathrm{h}$ & & \multicolumn{5}{|c|}{$\mathrm{cm}^{3} \mathrm{STP} / \mathrm{g} \mathrm{H}_{2} \mathrm{O}$} & {$[-]$} & {$[-]$} & & ${ }^{\circ} \mathrm{C}$ & $\%$ \\
\hline $\mathrm{Fb} 1-\mathrm{I}$ & 3 & $\mathrm{U}$ & 4.81 & 1.94 & 3.04 & 6.65 & 8.92 & 0.2737 & 0.1004 & $\mathrm{UA}(\mathrm{T}, \mathrm{A})$ & $20.9 \pm 0.2$ & 9.9 \\
\hline Fm1-II & 3 & $\mathrm{U}$ & 4.45 & 1.79 & 3.01 & 6.68 & 9.06 & 0.2740 & 0.1025 & $\mathrm{UA}(\mathrm{T}, \mathrm{A})$ & $20.3 \pm 0.2$ & 1.1 \\
\hline Fb1-III & 6 & U-D-U & 4.89 & 1.96 & 3.19 & 7.25 & 9.76 & 0.2756 & 0.1020 & $\mathrm{CE}(\mathrm{A}, \mathrm{F})$ & 20 & 10.2 \\
\hline Fb1-IV & 28 & U-D-U & 4.84 & 1.98 & 3.05 & 6.67 & - & 0.2697 & 0.1032 & $\mathrm{CE}(\mathrm{T}, \mathrm{A}, \mathrm{F})$ & $21.6 \pm 1.9$ & 12.9 \\
\hline $\mathrm{Fb} 2$ & 4 & $\mathrm{U}$ & 4.79 & 1.94 & 3.06 & 6.59 & 8.89 & 0.2725 & 0.1023 & $\mathrm{UA}(\mathrm{T}, \mathrm{A})$ & $20.8 \pm 0.2$ & 10.0 \\
\hline Fb3-I & 0.08 & $\mathrm{U}$ & 4.77 & 1.95 & 3.06 & 6.67 & 9.17 & 0.2703 & 0.1021 & $\mathrm{UA}(\mathrm{T}, \mathrm{A})$ & $20.4 \pm 0.1$ & 10.0 \\
\hline Fb3-II & 4 & $\mathrm{U}$ & 4.94 & 2.01 & 3.11 & 6.84 & 9.06 & 0.2710 & 0.1024 & $\mathrm{UA}(\mathrm{T}, \mathrm{A})$ & $20.0 \pm 0.1$ & 13.2 \\
\hline Fm3-III & 4 & $\mathrm{U}$ & 4.43 & 1.79 & 3.10 & 6.83 & 9.02 & 0.2731 & 0.1022 & non & - & $0.8 *$ \\
\hline Fb3-VI & 7.5 & U-D-U & 4.80 & 1.97 & 3.07 & 6.70 & 8.91 & 0.2686 & 0.1018 & $\mathrm{CE}(\mathrm{T}, \mathrm{A}, \mathrm{F})$ & $21.4 \pm 1.3$ & 12.4 \\
\hline $\mathrm{Fb} 4-\mathrm{I}$ & 4.5 & $\mathrm{U}$ & 4.95 & 2.03 & 3.15 & 6.92 & 9.38 & 0.2700 & 0.1024 & $\mathrm{UA}(\mathrm{T}, \mathrm{A})$ & $19.3 \pm 0.2$ & 13.2 \\
\hline Fb4-II & 24 & U-D-U-D-U & 4.98 & 2.03 & 3.15 & 6.69 & 9.20 & 0.2704 & 0.1024 & non & - & $14.4^{*}$ \\
\hline Fbp5 & 4 & $\mathrm{U}$ & 4.67 & 1.91 & 3.06 & 6.74 & 9.20 & 0.2707 & 0.1023 & $\mathrm{UA}(\mathrm{T}, \mathrm{A})$ & $20.0 \pm 0.1$ & 7.3 \\
\hline Fbpp6-I & 4 & $\mathrm{U}$ & 4.71 & 1.95 & 3.08 & 6.79 & 9.13 & 0.2677 & 0.1024 & $\mathrm{CE}(\mathrm{T}, \mathrm{A}, \mathrm{F})$ & $20.6 \pm 0.9$ & 10.2 \\
\hline Fbpp6-II & 30 & U-D-U & 4.70 & 1.96 & 3.13 & 6.78 & 9.06 & 0.2552 & 0.1024 & $\mathrm{PR}(\mathrm{T}, \mathrm{A}, \mathrm{F})$ & $20.0 \pm 0.3$ & 10.0 \\
\hline Fbpp6-III & 52 & U-D-U-D-U & 4.61 & 1.92 & 3.08 & 6.74 & 9.18 & 0.2652 & 0.1025 & $\mathrm{PR}(\mathrm{T}, \mathrm{A}, \mathrm{F})$ & $20.0 \pm 0.2$ & 8.0 \\
\hline $\mathrm{Fb} 7 \mathrm{Ctrl}$ & 65 & $\mathrm{U}$ & 4.92 & 2.02 & 3.11 & 6.66 & 9.10 & 0.2737 & 0.1023 & $\mathrm{CE}(\mathrm{T}, \mathrm{A})$ & $21.3 \pm 1.2$ & 14.8 \\
\hline Fb8 Ctrl & 192 & $\mathrm{U}$ & 4.35 & 1.87 & 3.16 & 6.92 & 9.28 & 0.2568 & 0.1025 & $\mathrm{PR}(\mathrm{T}, \mathrm{A}, \mathrm{F})$ & $19.1 \pm 0.5$ & 4.4 \\
\hline Fm9 & 7 & U-D-U & 4.39 & 1.82 & 3.08 & 6.87 & 9.12 & 0.2671 & 0.1021 & $\mathrm{UA}(\mathrm{T}, \mathrm{A})$ & $19.3 \pm 0.2$ & 1.5 \\
\hline Fm10 & 24 & U-D-U & 4.34 & 1.80 & 3.04 & 6.63 & 8.95 & 0.2663 & 0.1012 & $\mathrm{UA}(\mathrm{T}, \mathrm{A})$ & $20.2 \pm 0.4$ & 1.3 \\
\hline Fm11 & 24 & U-D-U & 4.37 & 1.83 & 3.08 & 6.88 & 9.00 & 0.2642 & 0.1024 & $\mathrm{UA}(\mathrm{A})$ & 20 & 1.4 \\
\hline Fm12 & 24 & U-D-U-D-U & 4.34 & 1.82 & 3.03 & 6.65 & 8.97 & 0.2636 & 0.1023 & $\mathrm{UA}(\mathrm{T}, \mathrm{A})$ & $19.9 \pm 0.2$ & 2.3 \\
\hline Fm13 & 28 & U-D-U-D-U & 4.39 & 1.82 & 3.02 & 6.65 & 8.77 & 0.2672 & 0.1024 & $\mathrm{UA}(\mathrm{T}, \mathrm{A})$ & $20.3 \pm 0.2$ & 2.4 \\
\hline Fm14 & 46 & $\begin{array}{c}\text { U-D-U-D- } \\
\text { U-D-U }\end{array}$ & 4.42 & 1.83 & 3.00 & 6.68 & 8.75 & 0.2663 & 0.1019 & $\mathrm{UA}(\mathrm{T}, \mathrm{A})$ & $20.5 \pm 0.2$ & 3.5 \\
\hline Fm15 & 50 & $\begin{array}{l}\text { U-D-U-D- } \\
\text { U-D-U-D-U }\end{array}$ & 4.42 & 1.84 & 3.03 & 6.800 & 8.96 & 0.2652 & 0.1031 & $\mathrm{UA}(\mathrm{T}, \mathrm{A})$ & $20.0 \pm 0.2$ & 3.5 \\
\hline Equi & - & - & 4.29 & 1.76 & 2.97 & 6.67 & 9.06 & 0.2679 & 0.1023 & $\mathrm{~T}$ & $20.4 \pm 0.1$ & - \\
\hline
\end{tabular}

Sample: F: Fluctuation experiment. m, b: Sample taken from the middle outlet or the bottom outlet of the column. p: Quartz sand packed in the column according to Stauffer \& Dracos (1986). pp: Quartz sand packed and not exchanged and dried after preceding experiment. Ctrl: Control samples. Equi: Average concentration of the equilibrated water used in the experiments.

ST: Sampling time after experiment start.

Sampling History: U: Up, water level rise (saturation step), D: Down, water level fall (drainage step).

Excess Air Model: UA: Unfractionated excess air model. CE: Closed system equilibration model (Aeschbach-Hertig et al., 2000). PR: Partial re-equilibration model (Stute et al., 1995).

T predicted: Noble gas temperature. If $\mathrm{T}$ is not included in the optimization procedure, it is set to $20^{\circ} \mathrm{C}$.

$\Delta \mathrm{Ne}$ : Ne supersaturation with regard to the noble gas temperature. For samples that could not be fitted using the available excess air models $(*)$, $\Delta \mathrm{Ne}$ was calculated assuming a $\mathrm{T}$ of $20^{\circ} \mathrm{C}$.

water correspond to a well constrained noble gas temperature of $20.4 \pm 0.1^{\circ} \mathrm{C}$.

\subsection{Water Throughflow}

All throughflow samples were taken from the bottom outlet of the columns whereby the water level was at constant height in all experiments. The results are shown in Figure 2a. Starting from air-saturated water $\mathrm{ASW}$ at $20{ }^{\circ} \mathrm{C}$ and $435 \mathrm{~m}$ a. s. 1., all sample concentrations in the $\mathrm{He}-\mathrm{Ar}$-plot fall between the dotted excess air line defining concentrations after addition of different amounts of pure air $\left(\mathrm{ASW}\left(20^{\circ} \mathrm{C}\right)+\mathrm{Air}\right)$ and the dashed line that denotes solubility equilibrium concentrations for increasing pressure $\left(\mathrm{ASW}\left(20^{\circ} \mathrm{C}\right)+\mathrm{P}\right)$. To explain these increased concentrations, additional air has to be forced to dissolve in excess of atmospheric solubility equilibrium. But the excess composition deviates from pure, unfractionated excess air: the measured Ar concentrations are with respect to He too large to be explained by unfractionated excess air at the given temperature, therefore the excess composition of the throughflow samples must be fractionated. Using NOBLE, the excess patterns in 14 samples match the prognosis of the CE-model, and 6 samples contain pure unfractionated excess air. In general, the noble gas temperatures predicted by the different gas exchange models agree well with the air temperature of the laboratory.

Within the throughflow experimental series, the influence of the flow velocity, the substrate and the timing of sampling as a function of duration of the experiment on the dissolved gas composition were investigated (Table 4). No obvious correlation of flow velocity and dissolved noble gas concentrations is observable. Although the flow velocity varied between $10 \mathrm{~cm} / \mathrm{h}$ and $110 \mathrm{~cm} / \mathrm{h}$, neither the amount of supersaturation nor the relative gas composition show a functional relation to the flow velocity of the respective experiment. The size of the quartz sands also seems to have no influence on the dissolved noble gas concentrations in the samples (identified by $\mathrm{M}, \mathrm{C}, \mathrm{F}$ in Table 4).

Time series samples that were taken during the same experiment at different times give evidence that the noble gas concentrations change with time elapsed since the beginning of the experiment (Fig. 3). The concentrations of the light noble gases $\mathrm{He}$ and $\mathrm{Ne}$ tend to increase with time whereas the concentra- 

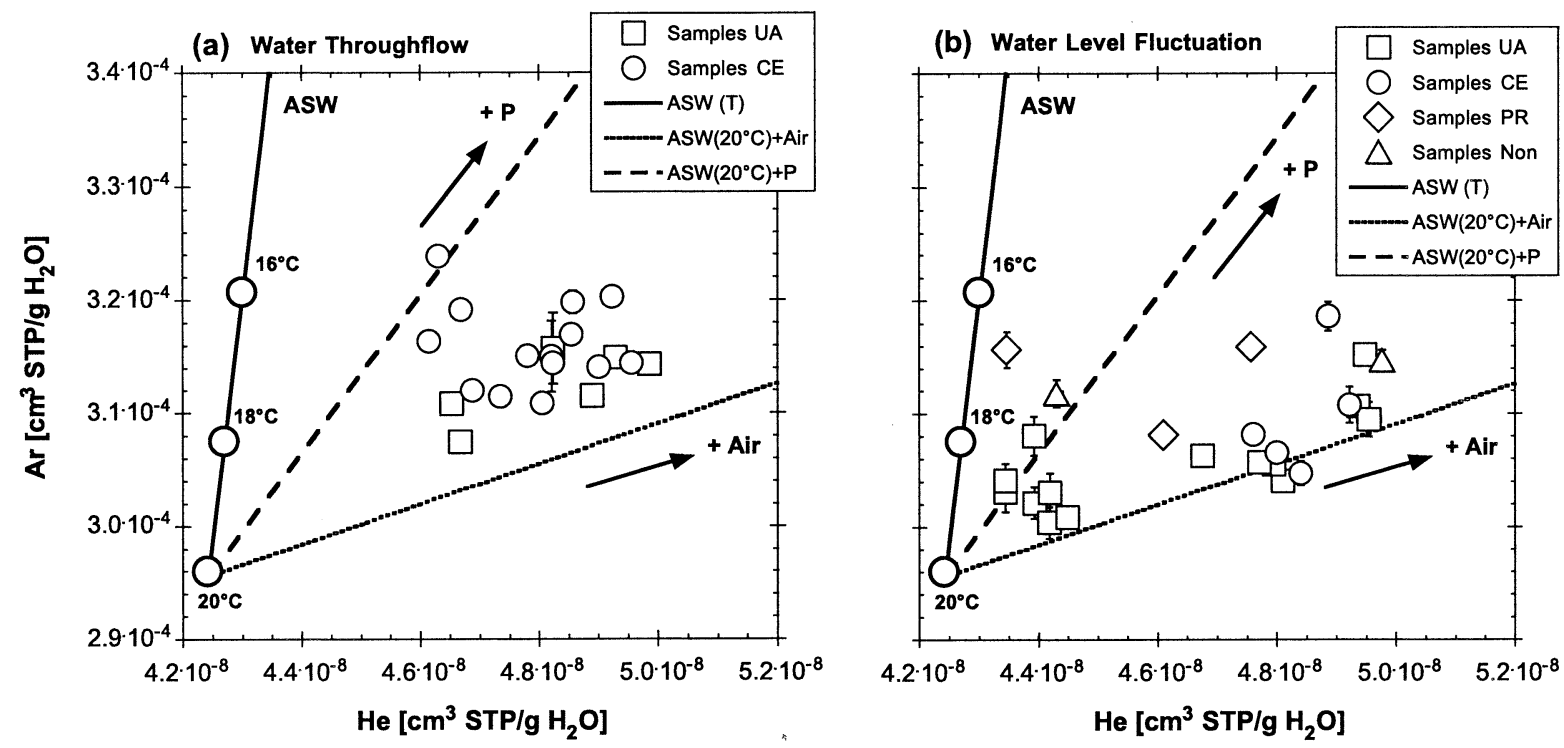

Fig. 2. Measured He and Ar concentrations of (a) the throughflow experiments and (b) the water level fluctuation experiments. In addition, the respective conceptual gas exchange model compatible with the measured noble gas concentrations is given for each sample.

tions of the heavy noble gases $\mathrm{Ar}$ and $\mathrm{Kr}$ tend to decrease (Table 4). Correspondingly, the CE-model parameters that describe the effect of fractionation evolve with time (Table 6). In the $24 \mathrm{~h}$ series TM7, TF10 and TC11, decreasing values of $F_{C E}$ and the partial dissolution parameter $v$ reflect the enhanced reduction of entrapped air with increasing experiment duration. Even the amount of entrapped air $A_{C E}$ seems to decrease with time, although a conclusive interpretation is not feasible considering the relatively large errors. In the two samples from series TM8 modeled under CE-assumptions, the parameters $F_{C E}$ and $v$ do not give statistically significant evidence of the reduction of entrapped air.

In all throughflow samples, the model parameter $q$ describing the ratio of the dry gas pressure in the trapped gas to that in the free atmosphere remains constant within the $2 \sigma$ level. As $q$ is a measure for the pressure acting on the entrapped air, this reflects the fact that the water level in the columns was kept at constant height during the experiments.

\subsection{Water Level Fluctuations}

The results from the water level fluctuation experiments are shown in Figure 2b. Two different groups of samples can be distinguished. The first group with relatively small He supersaturations comprises all samples that were taken from the middle outlet of the columns. The second group having signif-
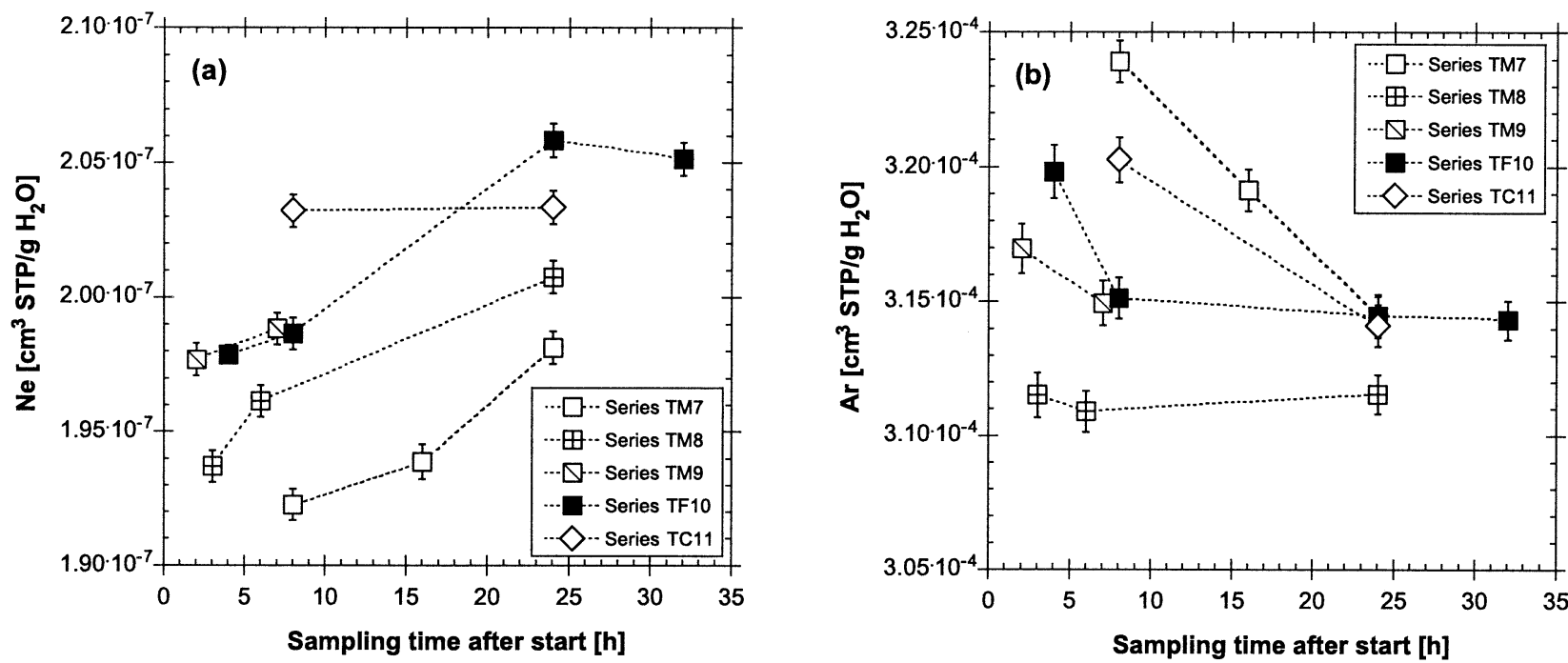

Fig. 3. Temporal evolution of the dissolved concentrations of (a) Ne and (b) Ar in the throughflow timeseries experiments. While the Ne concentrations tend to increase with time, the Ar concentrations decrease. 
Table 6. Parameters for the CE-modeled timeseries throughflow samples

\begin{tabular}{|c|c|c|c|c|c|c|}
\hline Sample & ST & $\begin{array}{c}\text { Excess air } \\
\text { model }\end{array}$ & $\begin{array}{c}\mathrm{A}_{\mathrm{CE}} \\
{\left[10^{-3}\right]} \\
\end{array}$ & $\mathrm{F}_{\mathrm{CE}}$ & $\mathrm{q}(\mathrm{T}, \mathrm{A})$ & $\mathrm{v}(\mathrm{T}, \mathrm{A})$ \\
\hline & $\mathrm{h}$ & & $\mathrm{cm}^{3} / \mathrm{g} \mathrm{H}_{2} \mathrm{O}$ & {$[-]$} & {$[-]$} & {$[-]$} \\
\hline TM7-I & 8 & $\mathrm{CE}$ & $91 \pm 84$ & $0.925 \pm 0.007$ & 1.066 & 0.987 \\
\hline TM7-II & 16 & $\mathrm{CE}$ & $40 \pm 35$ & $0.906 \pm 0.016$ & 1.070 & 0.969 \\
\hline TM7-III & 24 & $\mathrm{CE}$ & $25 \pm 19$ & $0.852 \pm 0.025$ & 1.097 & 0.934 \\
\hline TM8-I & 3 & $\mathrm{CE}$ & $20 \pm 18$ & $0.869 \pm 0.032$ & 1.077 & 0.936 \\
\hline TM8-II & 6 & $\mathrm{CE}$ & $15 \pm 12$ & $0.833 \pm 0.042$ & 1.085 & 0.903 \\
\hline TM9-I & 2 & $\mathrm{CE}$ & $24 \pm 17$ & $0.824 \pm 0.031$ & 1.115 & 0.919 \\
\hline TF10-I & 4 & $\mathrm{CE}$ & $17 \pm 8$ & $0.834 \pm 0.021$ & 1.091 & 0.910 \\
\hline TF10-II & 8 & $\mathrm{CE}$ & $14 \pm 6$ & $0.835 \pm 0.038$ & 1.081 & 0.903 \\
\hline TF10-III & 24 & $\mathrm{CE}$ & $7 \pm 3$ & $0.702 \pm 0.031$ & 1.096 & 0.769 \\
\hline TC11-I & 8 & $\mathrm{CE}$ & $12 \pm 9$ & $0.790 \pm 0.028$ & 1.096 & 0.866 \\
\hline TC11-II & 24 & $\mathrm{CE}$ & $8 \pm 3$ & $0.742 \pm 0.022$ & 1.090 & 0.810 \\
\hline
\end{tabular}

Sample: T: Throughflow experiment. M: Medium-sized quartz sand (diameter 0.315-0.63 mm). C: Coarse quartz sand (diameter 1.0-1.7 mm). F: Fine quartz sand (diameter $0.1-0.3 \mathrm{~mm}$ ).

ST: Sampling time after start of the experiment.

$\mathrm{A}_{\mathrm{CE}}$ : Amount of intially entrapped air according to the CE-model.

$\mathrm{F}_{\mathrm{CE}}$ : Degree of reduction of the amount of initially entrapped air A due to partial dissolution $v$ and compression $1 / \mathrm{q}: \mathrm{F}=v / \mathrm{q}$.

$\mathrm{q}(\mathrm{T}, \mathrm{A})$ : Relative pressure increase due to hydrostatic pressure that exert on the entrapped air. Within the $2 \sigma$ niveau, $\mathrm{q}$ can be considered as being constant in all samples.

$\mathrm{v}(\mathrm{T}, \mathrm{A})$ : Degree of partial dissolution of the entrapped air bubbles.

icantly higher He concentrations contains all samples that were taken from the bottom outlet of the columns. Again, all predicted noble gas temperatures agree well with the air temperature in the laboratory.

The location of the sampling port and hence the hydrostatic excess pressure on the sampled water dominates the amount of dissolved gas in the water level fluctuation experiments. Independent of the number of water level fluctuations preceding the sampling, the samples from the bottom of the columns contain a larger excess $(9.9 \%$ to $16.2 \% \Delta \mathrm{Ne})$ than the samples from the middle in which the lower hydrostatic pressure is reflected in the smaller $\Delta \mathrm{Ne}$ values of $1.1 \%$ to $4.4 \%$.

The number of alternating saturation and drainage cycles seems at least partially to influence the excess air composition of the samples. Generally, all samples that were taken after the first water saturation of a column within an experiment can be interpreted by the UA-model. After drainage and a second saturation step, the composition of the excess air in the bottom outlet samples differs from that in the middle outlet samples. The composition of the gas excess in the bottom samples is fractionated and can be explained either by the CE-model or by the PR-model. In contrast, samples from the middle of the columns show only a slight decrease in the dissolved $\mathrm{He}$ concentrations after the second saturation step. The interpretation of the noble gas patterns in these samples still obeys the UA-concept. Further drainage-saturation cycles do not alter the noble gas concentrations of samples from both sampling ports any more.

Of interest are the samples Fm9 to Fm15 from the middle outlet that were taken after multiple saturation steps. The supersaturation of $\mathrm{Ne}$ in most of these samples is larger than that of He. Conceptually, such an excess pattern can only be explained by diffusive loss of an initially dissolved gas excess as conceptualized in the PR-model. One would therefore expect these samples to be modeled correctly solely according to this diffusively controlled gas exchange approach. Nevertheless, all considered samples can satisfyingly be described by the UAmodel assuming no fractionation at all. The UA-model fits because generally only small amounts of supersaturation are present in these samples. Considering the analytical errors, all conceptual gas exchange models can in a statistically acceptable way reproduce the noble gas patterns in the samples, even if the ${ }^{20} \mathrm{Ne} /{ }^{22} \mathrm{Ne}$ and ${ }^{36} \mathrm{Ar} /{ }^{40} \mathrm{Ar}$ ratios are included in the optimization procedure. Therefore any further interpretation of the dissolved noble gases in these samples in terms of air-water partitioning is hampered.

While the inverse data analysis alone does not unequivocally distinguish between the different conceptual excess air models in the samples Fm9 to Fm15, the inclusion of elemental ratios, e.g., the ${ }^{4} \mathrm{He} /{ }^{20} \mathrm{Ne}$ ratio, may help to identify the mass transfer processes responsible for the observed concentration patterns. Based on the large differences in the elemental diffusivities (Table 1), diffusive changes of the gas composition affect the ${ }^{4} \mathrm{He} /{ }^{20} \mathrm{Ne}$ ratio much stronger than the ${ }^{20} \mathrm{Ne} /{ }^{22} \mathrm{Ne}$ and the ${ }^{36} \mathrm{Ar} /{ }^{40} \mathrm{Ar}$ ratio. Figure 4 shows the ${ }^{4} \mathrm{He} /{ }^{20} \mathrm{Ne}$ and ${ }^{22} \mathrm{Ne} /{ }^{20} \mathrm{Ne}$ ratios of all samples from water level fluctuation experiments. For the ${ }^{22} \mathrm{Ne} /{ }^{20} \mathrm{Ne}$ ratios, most samples arrange within error around the value of air-saturated water ASW (0.1023). The spread in the measured ${ }^{4} \mathrm{He} /{ }^{20} \mathrm{Ne}$ ratios is significantly larger than in the ${ }^{22} \mathrm{Ne} /{ }^{20} \mathrm{Ne}$ ratios. Samples in which the dissolved gas composition was altered by diffusive processes have ${ }^{4} \mathrm{He} /$ ${ }^{20} \mathrm{Ne}$ ratios smaller than that of air-saturated water ASW at $20^{\circ} \mathrm{C}(0.2672)$. Samples with a CE- or UA-type excess air composition fall within the range between ASW and the ratio of atmospheric air (0.3185). Interestingly, all samples taken from the middle outlet after multiple saturation steps have ${ }^{4} \mathrm{He} /{ }^{20} \mathrm{Ne}$ ratios smaller than $\mathrm{ASW}$ at $20^{\circ} \mathrm{C}$ (Table 5). This seems to indicate that these samples were affected by diffusive gas loss before sampling. As the ${ }^{4} \mathrm{He} /{ }^{20} \mathrm{Ne}$ ratios of the two samples from the middle outlet taken after the first water saturation show no evidence of a diffusive alteration in their 


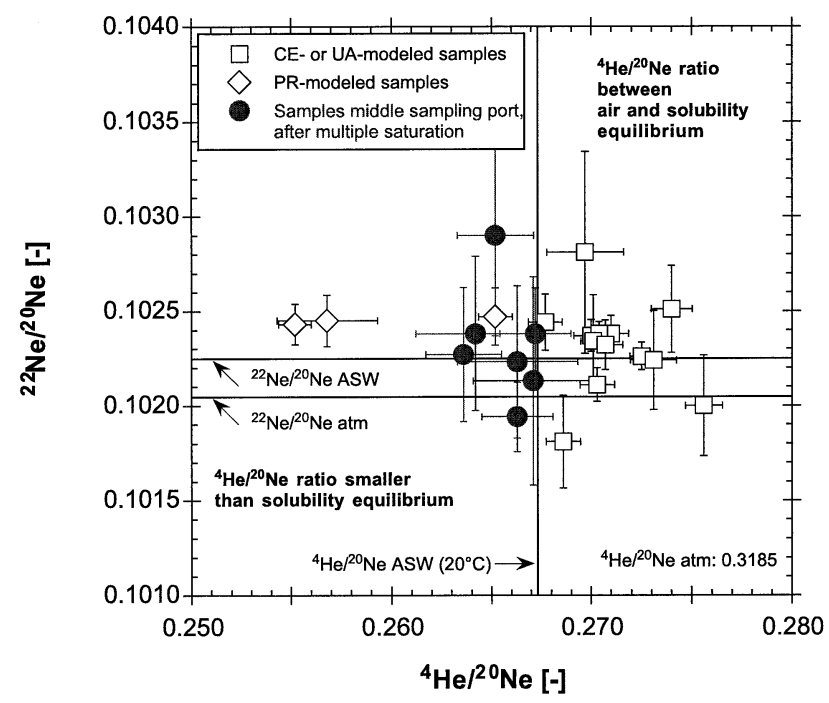

Fig. 4. $4 \mathrm{He} /{ }^{20} \mathrm{Ne}$ versus ${ }^{22} \mathrm{Ne} /{ }^{20} \mathrm{Ne}$ isotopic ratios of the water level fluctuation samples. While the ${ }^{22} \mathrm{Ne} /{ }^{20} \mathrm{Ne}$ ratios cluster around the value for air-saturated water $(0.1023)$, the ${ }^{4} \mathrm{He} /{ }^{20} \mathrm{Ne}$ ratios show a larger spread. All samples with an excess air composition according to the CE- or the UA-model have ${ }^{4} \mathrm{He} /{ }^{20} \mathrm{Ne}$ ratios greater than air-saturated water at $20{ }^{\circ} \mathrm{C}(0.2672)$. Samples with a PR-type fractionation of the noble gas composition have ${ }^{4} \mathrm{He} /{ }^{20} \mathrm{Ne}$ ratios smaller than 0.2672 as expected from the underlying diffusively controlled gas exchange concept. In addition, all water level fluctuation samples taken from the middle column outlet after two or more water saturation steps also show ${ }^{4} \mathrm{He} /{ }^{20} \mathrm{Ne}$ ratios smaller than 0.2672 , although their excess air composition is still compatible with unfractionated excess air.

gas composition, the gas loss present in the other samples apparently requires a drainage step before sampling.

\section{DISCUSSION}

The reproducible generation of excess air in laboratory experiments succeeded. By simulating the natural processes of infiltration (water throughflow) and groundwater level changes (water level fluctuations), significant supersaturations could be generated in the columns. The amounts of dissolved gas excess found in our experiments are in the same order of magnitude as in shallow aquifers with periodic groundwater level fluctuations of $\sim 1 \mathrm{~m}$ (Beyerle et al., 1999). The formation of excess in our experiments is related to either the complete or the partial dissolution of entrapped air bubbles. As in all porous media, air bubbles are entrapped whenever the quartz sand in the columns is water saturated. Although direct methods for the detection of entrapped air are scarce, the weight difference between a column after water level rise and the completely water saturated situation, achievable by $\mathrm{CO}_{2}$-flushing before water filling, evidence the presence of entrapped air. Due to the water overload, the air bubbles are subject to mass transfer with the surrounding water immediately after their entrapment. Therefore, one of the most prominent parameters influencing the amount of excess air is the hydrostatic pressure that can act on the entrapped air bubbles -an aspect that is also identifiable in groundwater samples (Aeschbach-Hertig et al., 2001). Regarding the composition of the dissolved gas excess, our experiments reveal various physical processes that constrain the formation and composition of the excess air component.

\subsection{Water Throughflow Experiments}

All throughflow samples have noble gas supersaturations in accordance with the prevailing hydraulic overload. For the CE-modeled samples, this overload is reflected in the $q$ parameter (Aeschbach-Hertig et al., 2001). Although $q$ is approximately constant within each single throughflow experiment, a random variation of $q$ between 1.115 and 1.066 is evident considering the different experiments (Table 6). Similarly, the concentrations of the light noble gases, in particular of He that reacts most sensitively to excess air and hence manifests the hydraulic excess pressure, show a random spread (Fig. 2a, for $\mathrm{He}$ ). Two reasons may explain this distribution. First, an inherent variability of the sand filling process and of the water saturation procedure is present. Although all experiments were performed completely in the same way, the assumption that each column has exactly the same porosity, the same amount of entrapped air and the same bubble size distribution of entrapped air is not realistic (Williams and Oostrom, 2000). Second, the sampling procedure does not allow collecting water from an exactly defined position within the column. The withdrawn water volume rather represents a vertical column segment of $10 \pm 5 \mathrm{~cm}$. Both aspects may lead to variations in the total amount of excess air that is documented in the light noble gas concentrations. But although the amount of excess air varies, the composition of the excess air is surprisingly constant as expressed by the CE-type fractionation of most samples.

To gain a better understanding of the underlying physical processes responsible for the formation of excess air in the throughflow experiments, the KBD-model was applied to simulate the dissolution of air bubbles in a soil column with advective water flow. The KBD-model was run with the following settings: Average diameter of entrapped air bubbles: 0.3 $\mathrm{mm}$; ratio of entrapped air volume and water volume: 0.09 ; porosity: 0.4 ; column height: $80 \mathrm{~cm}$; specific discharge: 10 $\mathrm{cm} / \mathrm{h}$; vertical discretization: $5 \mathrm{~cm}$; temporal discretization: $10 \mathrm{~s}$; water temperature: $20^{\circ} \mathrm{C}$; barometric pressure: $97425 \mathrm{~Pa}$. These settings correspond to the throughflow experiments with intermediate-sized quartz sand considering only the most frequent size of entrapped air bubbles. The simulation result is shown in Figure 5. Bubble radii of 4 depth classes are displayed with increasing time in Figure 5a. All entrapped bubbles are completely dissolved. The bubble extinction occurs first in the uppermost vertical box, followed by dissolution in the level below and so forth. This characteristic evolution is the result of the continuous vertical water flow in the column in which the uppermost box is refilled with water equilibrated at atmospheric pressure enhancing the effectiveness of the dissolution. The timescale for the dissolution of all entrapped air is in the order of $6 \mathrm{~d}$.

Figure $5 \mathrm{~b}$ shows the modeled relative changes in the dissolved noble gas concentrations at the column bottom. Starting from atmospheric solubility equilibrium, the concentrations are increasing nearly immediately after the simulation begins as a result of sudden application of pressure to the entrapped bubbles. After this first spike which is a result of the conceptualization of initial conditions within the KBD-model, the relative noble gas composition evolves differently for the light noble gases and the heavy noble gases. In a first phase, the relative $\mathrm{He}$ and $\mathrm{Ne}$ concentrations increase whereas $\mathrm{Ar}, \mathrm{Kr}$ and $\mathrm{Xe}$ rela- 

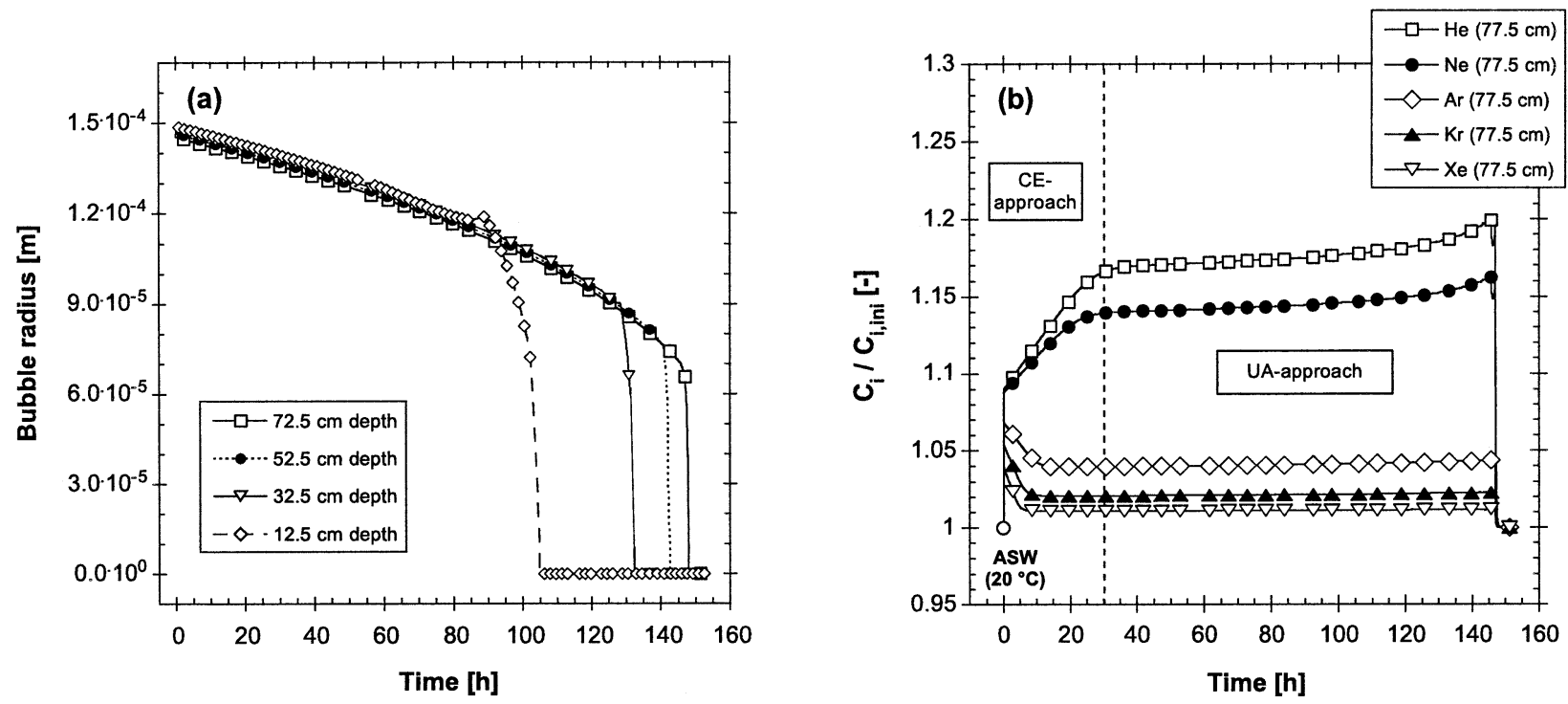

Fig. 5. Results for 4 depth levels from a run of the KBD-model with parameters defined by the throughflow experiments.

(a) Bubble radii with time. (b) Relative dissolved noble gas composition with time.

tively decrease. The dissolution process in this period is characterized by the adaptation of mass transfer to the hydraulic excess pressure. In the second, quasi steady-state period the amount of dissolved gas in each time step yields nearly constant dissolved noble gas concentrations. This plateau-like concentrations are reached the faster the better soluble the gas. On average, quasi steady-state conditions in the relative gas composition are reached within $30 \mathrm{~h}$. After the complete dissolution of all air bubbles, the noble gas concentrations are reaching again the atmospheric solubility equilibrium concentration of the water inflow.

If the gas compositions resulting from this KBD-model simulation are interpreted with the bulk gas exchange concepts, the first, non-steady phase can be described by the CE-model whereas the quasi steady-state phase matches the UA-approach. The modeled results agree well with the results from the time series experiments: Almost all samples from experiments with small flow velocities $(<30 \mathrm{~cm} / \mathrm{h})$ that were taken within $24 \mathrm{~h}$ after the start of the respective experiment have a noble gas composition that is described by a CE-type noble gas composition. These samples apparently stem from the first nonsteady-state dissolution phase. In contrast, the sample TF10-IV that was taken after $32 \mathrm{~h}$ has a purely atmospheric noble gas excess suggesting that the quasi steady-state phase has already been reached.

Figure 6 compares the results of the numerical simulation with the measured values of the time series from experiment TM7. The samples show the same temporal trend in the relative gas composition as predicted by the KBD-model: The light noble gases $\mathrm{He}$ and $\mathrm{Ne}$ are increasing whereas $\mathrm{Ar}, \mathrm{Kr}$ and $\mathrm{Xe}$ are decreasing. The temporal delay of the measured data in comparison to the model results most probably result from the range in the bubble sizes present in the column experiments. KBD-simulations with several bubble size classes showed that for each given depth only one bubble size can be stable with respect to the prevailing pressure. Therefore a rearrangement within the bubble sizes occurs immediately after the start of the simulation leading to only one respective bubble size persisting at each depth. As a result, the timescale for the dissolution of all entrapped air is prolonged compared to a single bubble size class. Besides the timing, the model prognosis for the concentrations is in a good agreement with the measured data if the analytical uncertainty is considered. Only for the relative $\mathrm{He}$ concentrations larger discrepancies are evident.

Numerical simulations with larger flow velocities show that the general concentration evolution is independent of the flow

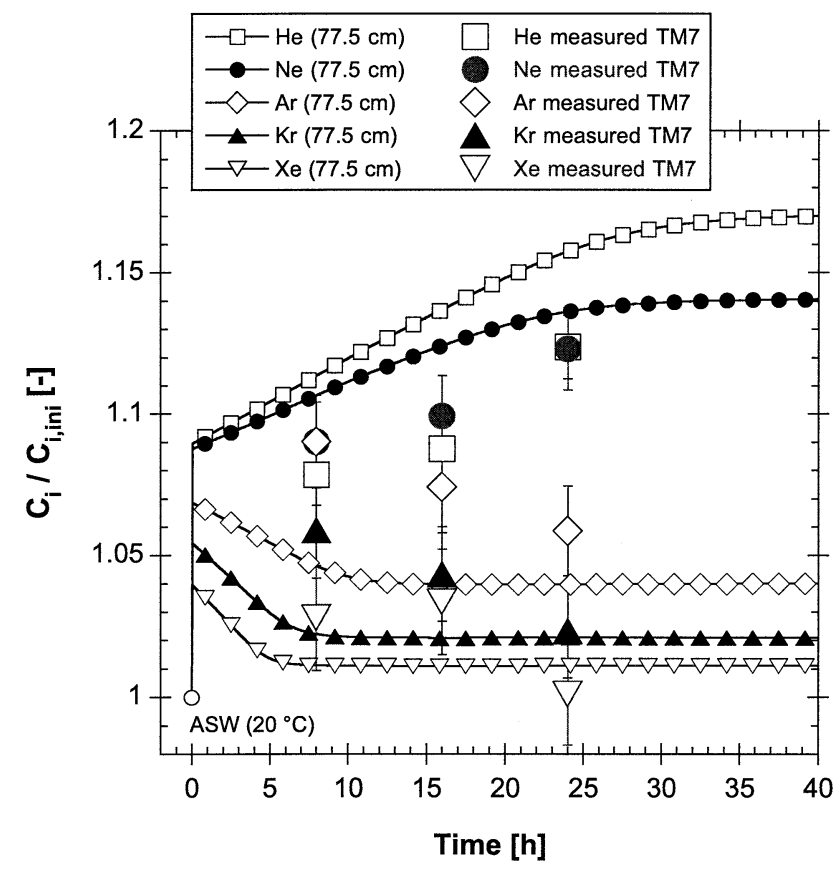

Fig. 6. Detail of the numerical simulation of the throughflow experiments including the measured results of experimental series TM7. Generally, the relative noble gas concentrations of the experiment show the same temporal evolution as predicted by the numerical model. 

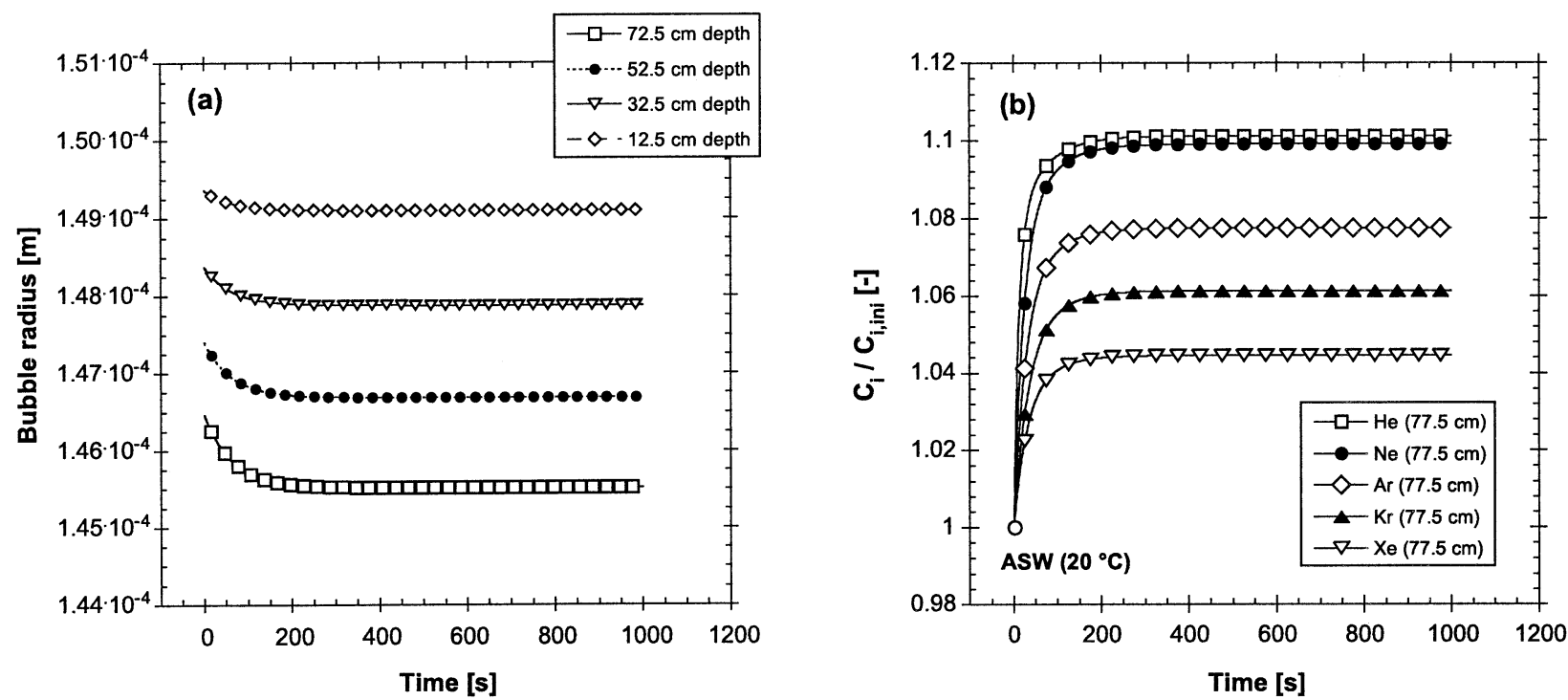

Fig. 7. Results from a KBD-model simulation with parameters defined by the water level fluctuation experiments after the first water saturation (no advective water flow). (a) Bubble radii with time. (b) Dissolved noble gas concentrations with time.

velocity. However, faster advective flow forces faster complete bubble dissolution and accelerates the transition from the initial non-steady state phase to the quasi steady-state situation. Therefore, as expected from the numerical simulation, in the experiments with flow velocities $\geq 30 \mathrm{~cm} / \mathrm{h}$, the quasi steadystate condition with constant relative elemental abundances is reached considerably faster (Sample TM1, TM3, TM4 and TM9-II).

\subsection{Water Level Fluctuation Experiments}

As in the water throughflow experiments, the hydrostatic pressure is the dominating parameter influencing the total amount of dissolved entrapped air. Samples from the middle outlet of the columns like Fm1-II and Fm3-III have significantly smaller supersaturations, especially in case of the light noble gases $\mathrm{He}$ and $\mathrm{Ne}$, than the samples from the bottom column outlet. The differences in the amounts of excess air between the two sampling ports as well as the absolute magnitude of the supersaturations agree well with the predictions by the CE- and UA-model respectively. The dissolved gas composition of most of the samples can be predicted correctly.

To analyze the experimental results and identify the underlying physical processes, the KBD-model was used to simulate the first saturation step, using the same initial parameters as for the throughflow simulation except that the advective water flow was set to zero. The results of the simulation are shown in Figure 7. As expected from the experiment design, the entrapped air bubbles dissolve only partially as the hydrostatic excess pressure alone is too small to force the entrapped air bubbles to dissolve completely. The entrapped air bubbles are partially dissolved until a new equilibrium is reached between the remaining entrapped air bubbles and the surrounding water. As shown in Figure 7a, it takes about ten minutes to establish equilibrium conditions. The experimental data support the modeled results. Sample Fb3-I taken 5 min. after the start of the experiment has not yet reached the final equilibrium conditions since the dissolved concentrations are still increasing towards the sample Fb3-II that was taken after $4 \mathrm{~h}$. Regarding the elemental composition, a temporal discrepancy between the simulation and the measured data exists. Similarly to the throughflow experiments, the distribution of the entrapped air volume in a range of bubble sizes delays the partial dissolution process and the attainment of the new steady-state condition. Since very small entrapped bubbles can be completely dissolved under closed-system equilibration conditions as well, the bottom samples taken within $4 \mathrm{~h}$ after the beginning of the experiment still show a unfractionated gas excess composition. Nevertheless, the majority of the excess air is already detectable after a few minutes in the experiments, which is in agreement with the results of the numerical simulation. The equilibration time increases generally with depth, i.e., with hydrostatic pressure, because according to Henry's law the maximum amount of gas that can be solved increases with increasing pressure.

Besides the hydrostatic pressure, the available amount of entrapped air and the entrapped bubble sizes seem to affect crucially the amount and the composition of excess air. Sample Fbp5 was taken in an experiment in which the quartz sand was packed to reach the most dense filling using the technique of Stauffer and Dracos (1986). In result, the porosity and hence the total amount of entrapped air in this column is smaller than in the other experiments. The measured dissolved concentrations of this packed column are significantly lower, especially in the case of the light noble gases $\mathrm{He}$ and $\mathrm{Ne}$, than in the bottom samples from other experiments. This suggests that the entrapped air volume available for dissolution in this experiment was smaller than in the unpacked columns. The porosity and hence the total amount of entrapped air therefore are important factors controlling the total amount of dissolved excess air. 

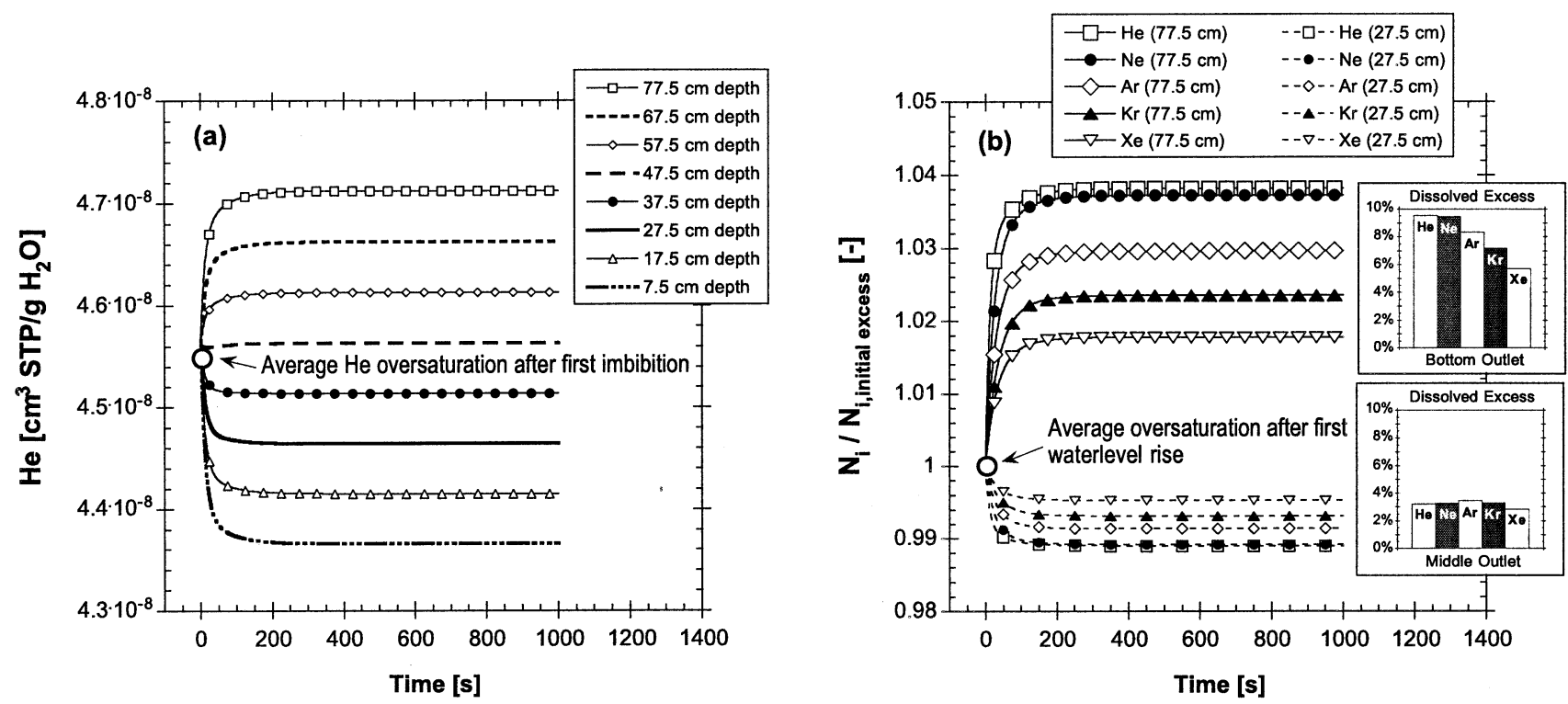

Fig. 8. Noble gas composition for a simplified water level fluctuation approach modeled by the KBD-model after refilling a soil column with an averaged supersaturated water. (a) The dissolved He concentrations for the lower part of the column still increase. In contrast, in the upper column section the He concentrations decrease as a result of the relatively smaller hydrostatic pressure, which implies that the mass flux in this upper section goes from the water into the entrapped air bubbles. (b) Relative changes in the amounts of the dissolved noble gases. The decrease in the upper column section and the increase in the lower part of the column are controlled by the gas solubilities. The relative change is the more effective, the lower the solubility of the gas is.

The following Fbpw6 series was conducted using the same column without replacing the sand. Initially the sand in this series was therefore not dry, but contained a residual amount of adsorbed water. In contrast to all other samples that were taken after the first water saturation, the sample Fbpw6-I has a fractionated gas excess pattern in accordance with the CEapproach. This documents that in the first saturation step of series Fbpw6 the smallest pores are occupied by immobile water and therefore not available for air entrapment. As a result, the entrapped air bubble size distribution is loosing its smallest sizes. Only larger air bubbles are entrapped which dissolve only partially under the given pressure conditions. The arising concentration pattern thus corresponds to the CE-concept. In contrast, the usual experimental procedure using dry sand allows air bubbles to be entrapped in the smallest pores during the first water saturation. These very small air bubbles can be completely dissolved, leading to a gas excess with pure atmospheric composition soon after the start of the experiment (e.g., Fb1-I, Fb2, Fb3-I).

From the experimental procedure and the application of the conceptual gas exchange models, it still cannot be explained why after the first water saturation step any further imbibition has no obvious influence on the dissolved gas composition at the column bottom. Furthermore, it is not clear why these further water saturation steps seem to produce a PR-type fractionation in the middle outlet samples. To explain the latter, a diffusive gas loss across either the water level in the column or through the acrylic column walls can be assumed. Considering the effective diffusion coefficients of the gases in a water-filled porous medium, which are approximately one order smaller than those in pure water, a solely diffusive gas transport from the middle of the column towards the water level cannot at all alter the gas composition on the timescale of our experiments. To test whether gas losses through the column wall are possible on the relevant temporal scale, we measured the dissolved noble gas content in two control samples, $\mathrm{Fb} 7 \mathrm{Ctrl}$ and $\mathrm{Fb} 8$ $\mathrm{Ctrl}$. The gas composition in sample $\mathrm{Fb} 7 \mathrm{Ctrl}$ taken $65 \mathrm{~h}$ after a first water saturation step shows no sign of diffusive gas loss. In contrast, sample Fb8 Ctrl taken after a 192 h stagnation period is characteristically fractionated: The light noble gases are depleted and the heavy noble gases are enriched, consequently the noble gas excess can only be explained by the PR-approach. Thus, diffusive gas losses through the column walls seem to occur on larger timescales, but for the time needed to perform our experiments, this kind of long-term diffusive loss is negligible.

To understand the processes leading to the observed noble gas pattern after multiple water saturation steps, we analyzed the dissolution kinetics employing the KBD-model (Fig. 8). Considering no-flow conditions, a simplified water level fluctuation approach was simulated: After the first water saturation, we assume that all the water is virtually withdrawn from the column and mixed completely. As a result, the concentrations in the water become the average of all concentrations from different column depths. This average approximately corresponds to the concentration in the geometric center of the column. In the second water saturation step, the column is refilled with this water, which is of average supersaturation with respect to atmospheric solubility equilibrium. Air bubbles consisting of pure atmospheric air are entrapped in this second step and equilibrate with the already supersaturated water component. The resulting new equilibrium concentrations in the water depend strongly on the applied hydrostatic pressure and on the gas solubility. At the bottom of the column, the concen- 
trations are hardly different from those of the first saturation step. The averaged dissolved gas excess applied in the second step is still smaller than the expected equilibrium concentrations for the given hydrostatic pressure at the bottom. Thus, in the lower part of the column, the dissolved concentrations still increase towards the newly established equilibrium condition as shown in Figure $8 \mathrm{a}$ for He. With decreasing hydrostatic pressure in the upper part of the column, the maximum amount of gas that can be dissolved in equilibrium with the entrapped air decreases. As a result, for smaller hydrostatic pressures the averaged gas excess in the applied water is already larger than expected from the new equilibrium with the entrapped air. In this case, the mass transfer is from water into the entrapped air bubbles as depicted for He in Figure 8a. The effectiveness of the dissolved gas composition to attain the new equilibrium conditions in the column is controlled by the solubility of the gases. Figure $8 \mathrm{~b}$ shows the relative changes in the amount of dissolved gas at the bottom and at the middle outlet of the column. The increase in the amount of dissolved gas at the bottom as well as the decrease in the middle outlet section of the column is the larger, the smaller the solubility of the gas. As a result, we find a new equilibrium concentration pattern for the middle column outlet that is characterized by a depletion of the light noble gases compared to the heavier ones, whereas at the column bottom the new equilibrium is nearly identical to that after the first saturation. The corresponding excess patterns are shown in Figure 8b. As expected, the composition of the dissolved gas excess at the column bottom is in agreement with the CE-model. In contrast, in the middle outlet we find the $\mathrm{He}$ supersaturation smaller than that of $\mathrm{Ne}$, and the $\mathrm{Ne}$ excess smaller than that of Ar. Such a dissolved concentration pattern can conceptually only be explained by the PR-approach. However, the shown result originates not from a diffusive loss of an initially dissolved gas excess across the water table, but from the differences in the solubilities of the gases that lead to a selective re-solution of a dissolved excess into entrapped air bubbles.

If we proceed, further drainage-wetting steps have virtually no additional influence on the noble gas abundance in the column. Since the processes leading to the final dissolved concentrations in the second saturation step are identical to those in all following saturation steps, also the attained equilibrium concentrations should be the same and no further changes in the dissolved gas composition can be expected from continued water saturations.

In conclusion, the numerical analysis allows to understand on a sound physical basis why after the second saturation step the dissolved noble gas composition of the middle outlet samples tends towards a pseudodiffusive PR-type fractionation whereas the composition of the bottom outlet samples do not show such a evolution, and why any further saturation steps have no effect on the composition and on the amount of the dissolved noble gases.

\subsection{Identification of Relevant Parameters in the Formation of Excess Air}

Combining the results from both experimental investigations and numerical simulations of the entrapped air dissolution, we are able to identify the following physical constraints control- ling the formation of excess air in quasi-saturated porous media:

1. Pressure: The total pressure exerted on the entrapped air is the dominating parameter responsible for the total amount of dissolved air The hydrostatic pressure together with the capillary pressure resulting from the curvature of the bubble surface force a new equilibrium condition between the entrapped bubbles and their surrounding water. In accordance with Henry's law, the noble gas excess increases with growing total pressure. Furthermore, the hydrostatic pressure can prevent the diffusive degassing of an initial dissolved gas excess. This explains why in groundwater studies samples with a partial re-equilibration signature can rarely be found. Since such studies aim to obtain the initial excess air composition, usually water from a certain depth within the aquifer is sampled. The hydrostatic pressure at that depth hinders the water to re-equilibrate to atmospheric conditions.

2. Flow regime: A predominantly vertical advective flow regime favors the complete dissolution of entrapped air bubbles and hence the formation of a dissolved gas excess with a composition that falls in the range between closed-system equilibration (first dissolution phase) and unfractionated excess air (second phase until complete dissolution) In stagnating waters, only closed-system equilibration conditions occur. Switching the flow regime between flow and no-flow conditions can lead to secondary gas exchange processes within the considered water column leading to a depletion of the light noble gases relative to the heavier ones.

The flow velocity defines the timescale of the entrapped air dissolution process. As documented by the throughflow experiments, the dissolved gas composition depends on the sampling time in relation to the flow velocity.

3. Total volume of initially entrapped air: The initially entrapped air volume limits the maximum possible amount of excess air being generated Whereas for no-flow conditions the entrapped air volume is usually not completely dissolved, complete dissolution of entrapped air seems to occur only on larger timescales and only under continuous vertical flow conditions. Soil parameters, such as the porosity and particle size distribution, influence the total available volume of entrapped air and thus affect the amount of excess air.

4. Entrapped air bubble size: The size distribution of the entrapped air bubbles influences the excess air composition Very small bubbles are much more likely subject to complete dissolution, resulting in unfractionated excess air. Larger bubbles have -depending on the flow velocity -significantly larger lifetimes and may therefore not be completely dissolved at all under natural flow conditions in aquifers. This situation favors the formation of fractionated excess air.

5. Initial composition of the dissolved gases: The initial composition of the dissolved gas is important for the mass transfer between entrapped air and water If infiltrating water already contains noble gases in excess as simulated by our imbibition-drainage experiments, and equilibrates with entrapped air bubbles of purely atmospheric composition, the heavy noble gases are significantly enriched compared to the 
light ones. Although the gas composition seems to resemble fractionation due to diffusive loss of an initial gas excess across the water table, it is the result of a new equilibrium state between initially supersaturated water and entrapped air and thus controlled by the gas solubilities.

6. Initial gas composition of entrapped air: Although not directly evidenced in our experiments, the initial composition of the gas in the entrapped air bubbles can also play a role in the composition of the resulting excess air While usually air-like gas abundances are assumed for entrapped air, it can be shown that the equilibration of a water volume in atmospheric solubility equilibrium with an entrapped gas phase that was preconditioned by a temporary partial dissolution step may lead to a fractionated excess air pattern in water comparable with the PR-approach.

\section{CONCLUSIONS}

In the present study the reproducible generation of excess air under defined, near natural boundary conditions in column experiments was successfully realized. The amounts of gas supersaturation range between $1.4 \% \Delta \mathrm{Ne}$ to $16.2 \% \Delta \mathrm{Ne}$ depending on the chosen experimental design. Using a combined approach of experimental investigations and modeling of gas exchange concepts and kinetics of air bubble dissolution in soil columns, excess air formation could be verified in a reproducible manner for the first time. The partial or the complete dissolution of entrapped air bubbles under quasi-saturated conditions is identified to be the mechanism responsible for the formation of excess air. The dominating parameter that is responsible for the total amount of dissolved air is the sum of hydrostatic and capillary pressure acting on the entrapped air bubbles. It governs the equilibrium between entrapped air and water in the quasi-saturated zone. Moreover, the total amount of entrapped air available for dissolution has an influence on the resulting amount of excess air. The composition of the generated excess air component is controlled by a number of factors: The water flow regime, the entrapped air bubble size distribution and the initially dissolved gas composition are reflected in the composition of the dissolved gas excess in a quasi-saturated porous medium.

Acknowledgments-The authors thank Urs Menet, Isotope Geology, ETH Zurich, for constructing the acrylic glass columns, and Quan Chen, MRI Laboratory, China National Petroleum Corporation \& Chinese Academy of Science, for providing the NMR analysis of the studied quartz sand.

\section{Associate editor: B. Marty}

\section{REFERENCES}

Aeschbach-Hertig W., Schlosser P., Stute M., Simpson H. J., Ludin A., and Clark J. F. (1998) A ${ }^{3} \mathrm{H} /{ }^{3} \mathrm{He}$ study of ground water flow in a fractured bedrock aquifer. Ground Water 36(4), 661-670.

Aeschbach-Hertig W., Peeters F., Beyerle U., and Kipfer R. (1999) Interpretation of dissolved atmospheric noble gases in natural waters. Water Res. Res. 35(9), 2779-2792.

Aeschbach-Hertig W., Peeters F., Beyerle U., and Kipfer R. (2000) Palaeotemperature reconstruction from noble gases in ground water taking into account equilibration with entrapped air. Nature 405, $1040-1044$.

Aeschbach-Hertig W., Beyerle U., Holocher J., Peeters F., Kipfer R. (2001). Excess air in groundwater as a potential indicator of past environmental changes. International Conference on the Study of Environmental Change Using Isotope Techniques. 34-36.

Andrews J. N. and Lee D. J. (1979) Inert gases in groundwater from the Bunter Sandstone of England as indicators of age and palaeoclimatic trends. J. Hydrol. 41, 233-252.

Benson B. B. and Krause D. (1980) Isotopic fractionation of helium during solution: A probe for the liquid state. J. Solution Chem. 9(12), 895-909.

Beyerle U., Aeschbach-Hertig W., Hofer M., Imboden D. M., Baur H., and Kipfer R. (1999) Infiltration of river water to a shallow aquifer investigated with ${ }^{3} \mathrm{H} /{ }^{3} \mathrm{He}$, noble gases and CFCs. J. Hydrol. 220(34), 169-185.

Beyerle U., Aeschbach-Hertig W., Imboden D. M., Baur H., Graf T., and Kipfer R. (2000) A mass spectrometric system for the analysis of noble gases and tritium from water samples. Env. Sci. Tech. 34(10), 2042-2050.

Broecker W. S. and Peng T.-H. (1974) Gas exchange rates between air and sea. Tellus. 26(1-2), 21-35.

Busenberg E. and Plummer N. L. (2000) Dating young groundwater with sulfur hexafluoride: Natural and anthropogenic sources of sulfur hexafluoride. Water Res. Res. 36(10), 3011-3030.

Chen Q. and Kinzelbach W. (2002) A NMR study of single- and two-phase flow in fault gouge filled fractures. J. Hydrol. 259(1-4), 236-245.

Christiansen J. E. (1944) Effect of entrapped air upon the permeability of soils. Soil Sci. 58(5), 355-365.

Clever H. L. (1979) Krypton, xenon and radon - gas solubilities. In Solubility data series (ed. I. U. o. P. a. A. Chemistry) Vol. 2, pp. 357. Pergamon Press.

Faybishenko B. A. (1995) Hydraulic behavior of quasi-saturated soils in the presence of entrapped air: Laboratory experiments. Water Res. Res. 31(10), 2421-2435.

Gröning M. (1989) Entwicklung und Anwendung einer neuen Probenahmetechnik für Edelgasmessungen an Grundwasser und Untersuchungen zum Luftüberschuss im Grundwasser. Diploma Thesis, Universität Heidelberg.

Heaton T. H. E. and Vogel J. C. (1979) Gas concentrations and ages of groundwaters in Beaufort Group sediments, South Africa. Water SA. 5(4), 160-170.

Heaton T. H. E. and Vogel J. C. (1981) "Excess air" in groundwater. $J$. Hydrol. 50, 201-216.

Heaton T. H. E., Talma A. S., and Vogel J. C. (1986) Dissolved gas paleotemperatures and (18)O variations derived from groundwater near Uitenhage, South Africa. Quat. Res. 25(1), 79-88.

Jähne B., Heinz G., and Dietrich W. (1987) Measurement of the diffusion coefficients of sparingly soluble gases in water. J. Geophys. Res. 92(C10), 10767-10776.

Mazor E. (1972) Paleotemperatures and other hydrological parameters deduced from gases dissolved in groundwaters, Jordan Rift Valley, Israel. Geochim. Cosmochim. Acta 36, 1321-1336.

Oana S. (1957) Bestimmung von Argon in besonderem Hinblick auf gelöste Gase in natürlichen Gewässern. J. Earth Sci. Nagoya Univ. 5, 103-105.

Osenbrück K. (1991) Laborversuche zur Bildung des Luftüberschusses im Grundwasser. Diploma Thesis, Universität Heidelberg.

Schlosser P., Stute M., Dörr C., Sonntag C., and Münnich K. O. (1988) Tritium ${ }^{\beta} \mathrm{He}$-dating of shallow groundwater. Earth Planet. Sci. Lett. 89, 353-362.

Schwarzenbach R. P., Gschwend P. M., and Imboden D. M. (1993) Environmental organic chemistry. John Wiley \& Sons, INC.

Stauffer F. and Dracos T. (1986) Experimental and numerical study of water and solute infiltration in layered porous media. J. Hydrol. 84, $9-34$.

Stute M. and Schlosser P. (1993) Principles and applications of the noble gas paleothermometer. In Climate Change in Continental Isotopic Records, (ed. P. K. Swart, K. C. Lohmann, J. McKenzie, and S. Savin) Vol. 78, pp. 89-100. American Geophysical Union.

Stute M., Talma A. S. (1998) Glacial temperatures and moisture transport regimes reconstructed from noble gases and delta ${ }^{18} \mathrm{O}$, Stampriet aquifer, Namibia. In Isotope techniques in the study of environmental change, edited by IAEA, pp. 307-318, Vienna, Austria. 
Stute M., Forster M., Frischkorn H., Serejo A., Clark J. F., Schlosser P., Broecker W. S., and Bonani G. (1995) Cooling of tropical Brazil $\left(5^{\circ} \mathrm{C}\right)$ during the Last Glacial Maximum. Science 269, $379-383$.

Stute M., Deák J., Révész K., Böhlke J. K., Deseö É., Weppernig R., and Schlosser P. (1997) Tritium $/{ }^{3} \mathrm{He}$ dating of river infiltration: An example from the Danube in the Szigetkös area, Hungary. Ground Water 35(5), 905-911.

Tegen I. (1988) Laborexperimente zur Tiefenverlagerung von Cäsium und zur Entstehung des Luftüberschusses im Grundwasser, Diploma Thesis, Universität Heidelberg.
Weiss R. F. (1970) The solubility of nitrogen, oxygen and argon in water and seawater. Deep-Sea Res. 17, 721-735.

Weiss R. F. (1971) Solubility of helium and neon in water and seawater. J. Chem. Eng. Data. 16(2), 235-241.

Weiss R. F. and Kyser T. K. (1978) Solubility of krypton in water and seawater. J. Chem. Eng. Data. 23(1), 69-72.

Williams M. D. and Oostrom M. (2000) Oxygenation of anoxic water in a fluctuating water table system: an experimental and numerical study. J. Hydrol. 230, 70-85.

Wilson G. B. and McNeill G. W. (1997) Noble gas recharge temperatures and the excess air component. Appl. Geochem. 12(6), 747-762. 